\title{
Lyophilisation of inactivated vaccines
}

\author{
(C) Alexander V. Komissarov*,**, Dmitry N. Bibikov*, Oksana A. Volokh*, \\ Sergey A. Badarin*, Nataliya V. Sinitsyna*, Nataliya I. Kostyleva*, \\ Aleksey K. Nikiforov*,**
}

* Russian Research Anti-Plague Institute «Microbe», Saratov, Russian Federation

${ }^{* *}$ N.I. Vavilov Saratov State Agrarian University, Saratov, Russian Federation

\begin{abstract}
A review of national and foreign scientific and patent literature, as well as the regulatory documents on the lyophilisation of inactivated vaccines, is presented. According to the State Register of Medicinal Products, all inactivated vaccines produced in dried form in the Russian Federation are obtained by freeze-drying. The excipients (drying media) used in the freeze-drying of vaccines are evaluated in terms of their qualitative and quantitative composition. A review of the features of the main stages of freeze-drying processes, e.g. freezing, sublimation (primary drying) and desorption (secondary drying) is given alongside an analysis of their distinctive features. The information on inactivated vaccines in the lyophilisate form registered in the Russian Federation is systematised. Available information on inactivated vaccines produced in the United States in the form of a lyophilisate is also presented. An analysis of the literature data reveals a significant variety of excipients used in lyophilisation. The influence of the sealing method of consumer packaging on the quality of preparations is considered, i.e. either in the oxygen or inert gas media or under vacuum. It is noted that the entire range of vaccines produced and registered in Russia is sealed under vacuum or in inert gas (i.e. in the absence of oxygen). A number of examples are cited to demonstrate the effect of technological freeze-drying process parameters on the quality of the preparations. It is shown that the preservation of a vaccine's properties during freeze-drying is influenced by a number of parameters, including the freezing rate and the temperature-time parameters of the primary drying and desorption processes. It is established that the correct selection of the qualitative and quantitative characteristics of the drying medium contributes to the preservation of the target properties of lyophilised preparations. The analysis of literature data allows the influence of the parameters described in the review to be considered when developing the technology for the production of immunobiological preparations for the prevention and treatment of infectious diseases.
\end{abstract}

Keywords: lyophilisation, inactivated vaccines, excipients, technological characteristics

Information about the article: Received April 8, 2019; accepted for publication September 5, 2019; available online September 30, 2019.

For citation: Komissarov A.V., Bibikov D.N., Volokh O.A., Badarin S.A., Sinitsyna N.V., Kostyleva N.I., Nikiforov A.K. Lyophilisation of inactivated vaccines. Izvestiya Vuzov. Prikladnaya Khimiya i Biotekhnologiya [Proceedings of Universities. Applied Chemistry and Biotechnology]. 2019, vol. 9, no. 3, pp. 403-419. (In Russian). DOI: 10.21285/2227-2925-2019-9-3-409-419

\section{Лиофилизация вакцин, не содержащих живых микроорганизмов}

\author{
() А.В. Комиссаров* ${ }^{* *}$, Д.Н. Бибиков*, О.А. Волох*, С.А. Бадарин*, \\ Н.В. Синицына*, Н.И. Костылева*, А.К. Никифоров*,** \\ * Российский научно-исследовательский противочумный институт «Микроб», \\ г. Саратов, Российская Федерация \\ ** Саратовский государственный аграрный университет им. Н.И. Вавилова, \\ г. Саратов, Российская Федерация
}


Резюме: Представлен обзор отечественной и зарубежной научной и патентной литературы, а также нормативных документов, посвященных вопросам лиофилизации вакцин, не содержащих живых микроорганизмов. По данным Государственного реестра лекарственных средств выявлено, что все вакцины, не содержащие живых микроорганизмов и выпускаемые в сухой форме в Российской Федерации, получены путем сублимационного высушивания. Дано представление о качественном и количественном составе вспомогательных веществ (сред высушивания), применяемых при сублимационной сушке вакцин. Дан обзор особенностей основных этапов сублимационного высушивания (замораживание, сублимация (первичное высушивание) и десорбция (вторичное высушивание) и проанализированы их отличительные черты. Систематизированы сведения о вакцинах, не содержащих живых микроорганизмов, в фоорме лиофилизата, зарегистрированных в Российской Федерации. Представлена доступная информация о вакцинах, не содержащих живых микроорганизмов, в фрорме лиофилизата, производимых в США. При анализе литературных данных выявлено существенное разнообразие используемых вспомогательных веществ, применяемых при лиофилизации. Рассмотрено влияние на качество препаратов способа герметизации потребительской упаковки - в среде кислорода, инертного газа или под вакуумом. Отмечено, что для всего спектра производимых и зарегистрированных в России вакцин применена герметизация под вакуумом или в среде инертного газа (то есть в отсутствие кислорода). На ряде примеров показано воздействие технологических параметров процесса сублимационной сушки на качество препаратов. Показано, что на сохраняемость свойств вакцин при сублимационной сушке оказывает влияние ряд параметров, к основным из которых можно отнести скорость замораживания, а также температурно-временные параметры процессов первичной сушки и десорбции. Установлено, что правильный подбор качественно-количественных характеристик среды высушивания способствует сохранению целевых свойств лиофилизируемых препаратов. Проведенный анализ данных литературы позволяет учесть влияние описанных в обзоре параметров при разработке технологии производства иммунобиологических препаратов для профилактики и лечения инфекционных заболеваний.

Ключевые слова: лиофилизация; вакцины, не содержащие живых микроорганизмов; вспомогательные вещества; технологические характеристики

Информация о статье: Дата поступления 8 апреля 2019 г.; дата принятия к печати 5 сентября 2019 г.; дата онлайн-размещения 30 сентября 2019 г.

Для цитирования: Комиссаров А.В., Бибиков Д.Н., Волох О.А., Бадарин С.А., Синицына Н.В., Костылева Н.И., Никифоров А.К. Лиофилизация вакцин, не содержащих живых микроорганизмов // Известия вузов. Прикладная химия и биотехнология. 2019. T. 9, N 3. C. 403-419. DOI: 10.21285/2227-2925-20199-3-403-419

\section{INTRODUCTION}

The first mention of the preparation and use of inactivated vaccines, i.e. vaccines not containing live microorganisms, dates back to the end of the 19th century [1]. American scientists Daniel Salmon and Theobald Smith showed that when a bacterial suspension of the Salmonella genus inactivated by heating at a temperature of $58-60{ }^{\circ} \mathrm{C}$ for 2 hours was introduced to experimental subjects (pigeons), it led to their insusceptibility to this infection, referred to at the time as "hog cholera" [2]. The first lyophilised inactivated vaccines, the technology for which was developed in the early 1960s, were the Rab-Avert and Rabipur rabies vaccines, prepared on the basis of the inactivated of the Flury LEP rabies virus [3].

One of the main quality indicators of vaccines, determining the formation of immunity against the disease is the specific activity, which is characterised by the presence and stability of antigens of various nature (proteins, capsular polysaccharides, oligosaccharides, etc.).
In a review article on lyophilisation of biopharmaceutical proteins, D.A. Gusarov cites the work M.J. Pikal [4] to state: "... the stability of preparations can be increased by converting them into solids using lyophilisation" [5]. The above statement is confirmed by the fact that the inactivated purified concentrated lyophilised cultural tick-borne encephalitis vaccine produced by Chumakov Federal Scientific Center for Research and Development of Immune-and- Biological Products of Russian Academy of Sciences has a shelf life of 3 years, while a similar vaccine in the form of a suspension manufactured by NPO Microgen can only be safely stored for 2 years.

According to the State Register of Medicinal Products (SRMP) ${ }^{1}$, all inactivated vaccines produced in dried form are obtained by freezedrying. However, it should be noted that freeze-

1 Государственный реестр лекарственных средств: справочник; в 2 т. (компл. из 4-х книг). М.: Медицинский совет, 2009. 2400 с. 
drying is not always a guarantee of preservation and stabilisation of the target properties of biological preparations during their storage [6]. As a rule, failures in this respect are due to the wrong choice of the main functional components of lyophilisation, such as technological parameters, qualitative and quantitative composition of the drying media, sealing conditions for the dried preparations, etc. In our opinion, this can be explained by the small number of national publications devoted to the systematisation of available information on the lyophilisation of a particular group of preparations, including inactivated vaccines. In this regard, the main objective of the present review is to generalise the data from the scientific and patent literature on the freeze-drying of inactivated vaccines.

\section{THE ANALYSIS OF BIOTECHNOLOGICAL FEATURES OF LYOFILISATION OF INACTI- VATED VACCINES}

The removal of moisture by lyophilisation, essentially sequential operations by which a substance is transfered into a solid state by means of freezing and dehumidification by negative pressure, can adversely affect the main characteristics of biological preparations, including vaccines. In most cases, lyophilisation conditions are chosen empirically, without taking the characteristics of the drying substance into account (for example, an unmotivated increase in the time of freezedrying), which may reduce the efficiency of the whole process, negatively affecting the quality of the product and ultimately increasing its cost.

Since any substance (i.e. biological preparation) can be subjected to a procedure such as lyophilisation, it is appropriate to provide a general brief description of this process.

Conventionally, the process of freeze-drying (lyophilisation) is differentiated according to three key stages: freezing, sublimation (primary drying) and desorption (secondary drying).

When undergoing freezing, a substance passes into a new phase having a different structure, on which the course of the subsequent lyophilisation stages depends, resulting in the formation of the desired characteristics of the finished preparation $[5,7,8]$. The freezing process can occur by the following mechanisms: crystallisation (when molecules or atoms are arranged into a regular order) or amorphisation, when such ordering is absent. There are also cases where these mechanisms are combined [7-9]. The structure of a solid affects the intensity of the processes of primary and secondary drying [10].

Under production conditions, freezing is generally carried out by placing the vessels containing the preparation on the shelf of a freeze-dryer, followed by its cooling to the required temperature typically using a linear mode of temperature decrease [11, 12]. The following stages are characteristic of crystallisation:
- crystal nucleation, which is determined primarily by the content of solid components in the solution and occurs after reaching a cryoscopic temperature unique for each substance [9];

- crystal growth that occurs when the substance cools to below cryoscopic temperatures. This results in the solid phase concentration leading to a decrease in the freezing temperature of the unfrozen solution [13].

For frozen products, processes occurring through crystallisation are characterised by eutectic temperature, while those occurring via amorphisation are determined by glass transition temperature. This is the minimal temperature at which solid and liquid phases are in equilibrium (a part of the cured substance (up to 10\%) is present in the form of a liquid). Any further decrease - typically by $2-10{ }^{\circ} \mathrm{C}$ - leads to the complete solidification of unbound moisture [9]. In a completely frozen solution, up to $20 \%$ of the unfrozen fraction is almost invariably present, tightly bound to the solid ingredients of substances by various bonds [5, 8].

The sublimation of the substance is initiated by providing a vacuum in the lyophiliser. In order to ensure a successful sublimation process, the vacuum pressure in the lyophiliser must be less than the saturated vapour pressure of the frozen product. The return of the released liquid vapour to a solid state occurs in the desublimator of the lyophilisation machine 20-40 ${ }^{\circ} \mathrm{C}$ lower than the temperature in the product chamber of the freeze-dryer [13, 14]. The duration of this stage depends on several defining characteristics:

- the height of the dried preparation (the greater this parameter, the longer the sublimation time [8]);

- the porosity of the frozen product, determined mainly by the temperature and duration of the freezing phase (an increase in porosity contributes to a more intensive process of vapour removal [9]);

- the surface area of the dried preparation (the intensity of the primary drying increases with increased area [5]);

- the shelf temperature of the food compartment - and, consequently, of the preparation itself (an increase in this parameter intensifies primary drying $)^{2}$.

The temperature of the substance should be less than or equal to its eutectic (glass transition) temperature (note that each substance has its own characteristic eutectic temperature values). Failure to ensure this may result in thawing and

2 Нежута А.А. Научное обоснование и методика разработки и совершенствования промышленной технологии сублимационного высушивания биопрепаратов: дис. ... д-ра биолог. наук: 03.00.23. Щелково, 2003. 243 с. 
foaming of the dried product. A consequence of this may be a loss of the biological product's mass during drying, as well as a general loss of its specific properties [8].

The end of the primary drying process coincides with the complete removal of frozen unbound moisture. However, a certain amount of bound, uncured moisture remains in the preparation, which must be removed at higher temperatures than during the sublimation process.

The authors of the study [15] have experimentally demonstrated that during secondary drying temperature loss, area and desorption time have a significant effect on a substance's mass loss on drying; moreover, this quantitative indicator does not depend on the vacuum pressure in the lyophiliser or the height of the dried product.

In the study [16], it is stated that loss on drying "... significantly affects the stability of the finished product during storage and the requirements for storage conditions".

The authors of the published research [17] concluded that the optimal secondary drying temperature-time and mass loss parameters should be individually experimentally justified for each biological preparation.

It has been experimentally shown that weak heating of the preparation lengthens the process of freeze-drying, while excessive heating can lead to thawing of the product and a subsequent deterioration of its properties. Thus, the problem of the correct selection of the temperature-time characteristics of freeze-drying appears to be relevant.

The effect of auxiliary components and their ratio on the persistence of the target properties of preparation subjected to freeze-drying is known. These substances used as drying media are represented by the following groups [18]:

- excipients (providing a matrix for the active pharmaceutical component);

- buffer solutions (creating the desired $\mathrm{pH}$ );

- tonicity regulators (ensuring the necessary osmotic pressure);

-structural modifiers (improving matrix properties for the better passage of removed moisture vapours);

- stabilisers, both cryo- and lyoprotectants (ensuring the protection of the active pharmaceutical component from excessive moisture removal and the negative effects of low temperatures);

- destruction inhibitors (preventing an increase in temperature that violates the structural integrity of the lyophilised preparation).

The most commonly used excipients on the lyophilisation of live vaccines are presented in the article [19].

The sealing conditions of dry preparations obtained by freeze-drying in the primary packaging process are of great importance for main- taining their target properties. In 1977, L. Rey advised that lyophilised biological samples be stored either under vacuum or in the presence of a neutral gas such as nitrogen or argon [20].

The primary consumer packaging used for freeze-dried preparations is either in the form of ampoules or vials. An examination of the SRMP data revealed the predominant use of vials (up to $90 \%$ ). The most likely explanation for this is that procedure for sealing ampoules at the conclusion of the freeze-drying process involves their removal from the lyophiliser with additional soldering and, if necessary, preliminary vacuum pumping or the introduction of an inert gas. However, modern industrial lyophilisation equipment allows vials to be sealed directly in the freeze-dryer chamber, including under vacuum or inert gas, simplifying the production process and consequently reducing the cost of preparations.

When examining the SRMP data, it was revealed that 44 of 300 vaccines for human use are produced in the lyophilisate form. Of these, 25 are live vaccines, while the number of inactivated vaccines is 19 (of which 10 are Russianmade). According to the information provided on the website of Rosselkhoznadzor (Federal Service for Veterinary and Phytosanitary Surveillance) of the Russian Federation, 637 preparations are produced for veterinary medicine, 270 of which are live vaccines in the dried form, while 13 are inactivated vaccines containing no live organisms.

Table 1 summarises the data on the lyophilisation process for inactivated vaccines used in human medicine. The information available in SRMP and in the State Pharmacopoeia of the Russian Federation ${ }^{3}$ is used alongside manufacturer data to systematise the data on the preparations. Table 2 provides the information on inactivated vaccines produced in the USA in the lyophilisate form taken from open sources [3].

As can be seen from an analysis of the data presented in Table 2, the residual moisture of the vaccines ranges from 2 to $3 \%$. The entire spectrum of vaccines registered in Russia is characterised by the sealing of primary packages in oxygen-free media (under vacuum or in an inert gas). For the vast majority of domestic preparations, consumer packaging is represented by ampoules (8 out of 10 items). Conversely, 100\% of foreign vaccines are available in vials. The height of the lyophilised product ranges from 0.12 to $10 \mathrm{~mm}$. The variety of excipients used in the preparation of these produces is significant.

3 Государственная фармакопея Российской Федерации. XIV-е изд.; в 4 т. 2018. T. IV [Электронный ресурс] / Министерство здравоохранения РФ. Федеральная электронная медицинская библиотека. URL: http://resource.rucml.ru/feml/pharmacopia/14_4/HTML/index.html (21.04.2019) 
Komissarov A.V., Bibikov D.N., Volokh O.A., et al. Lyophilisation of inactivated...

Комиссаров А.В., Бибиков Д.Н., Волох О.А. и др. Лиофилизация вакцин, не содержащих...

$\frac{5}{\frac{1}{0}}$

\begin{tabular}{|c|c|c|c|c|c|c|c|c|}
\hline 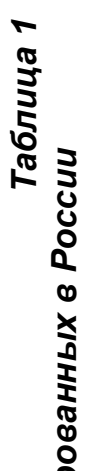 & 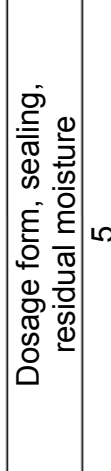 & 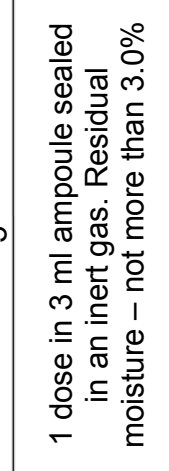 & 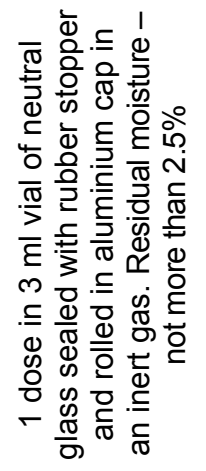 & 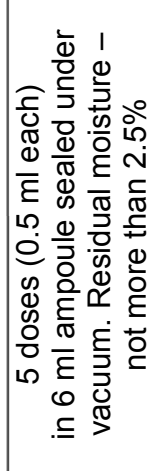 & 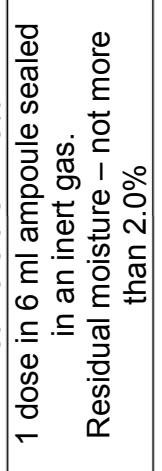 & 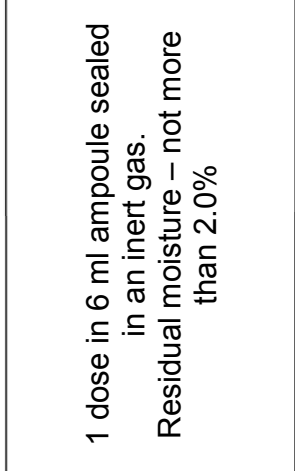 & 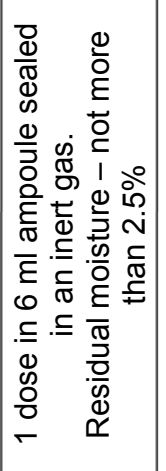 & 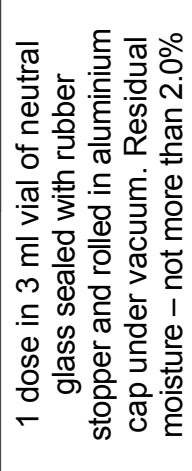 \\
\hline 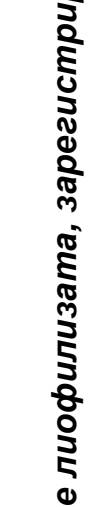 & 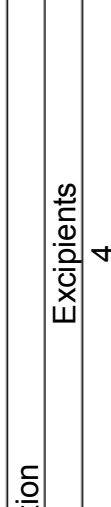 & 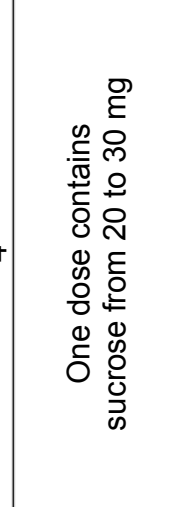 & 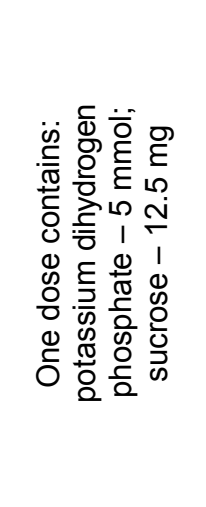 & 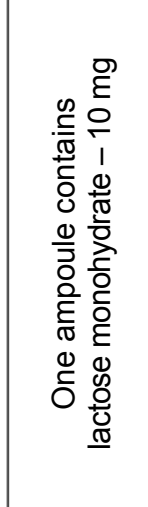 & 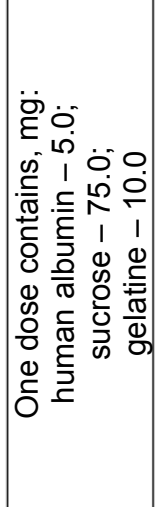 & 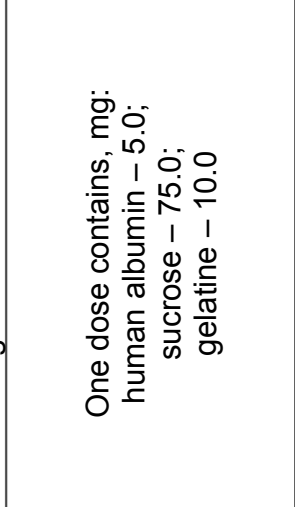 & 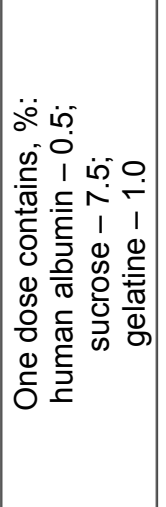 & 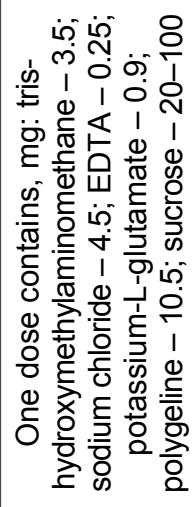 \\
\hline 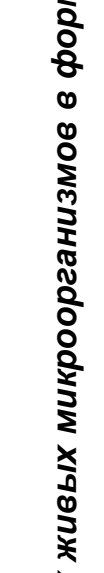 & 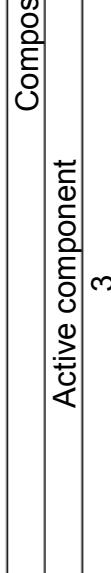 & 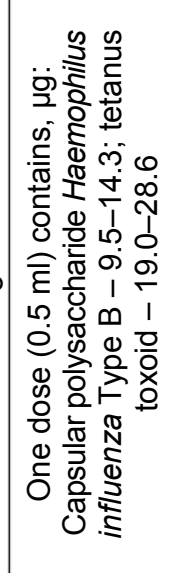 & 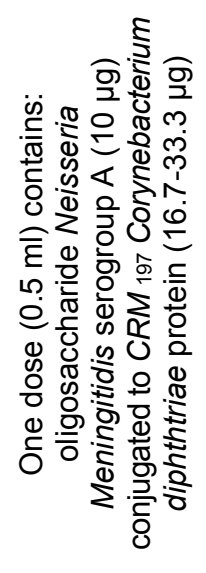 & 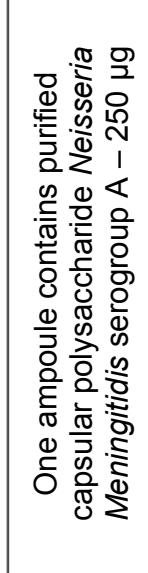 & 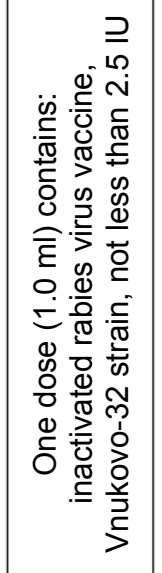 & 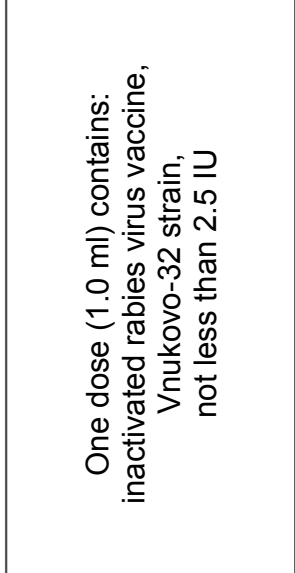 & 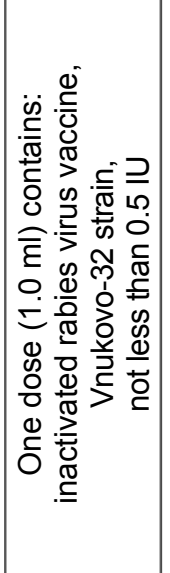 & 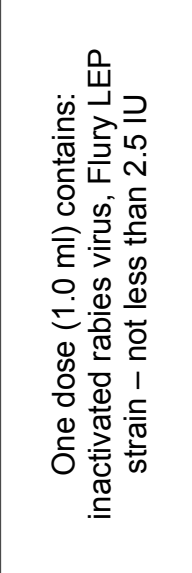 \\
\hline 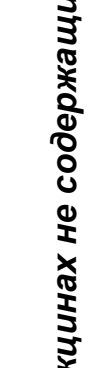 & 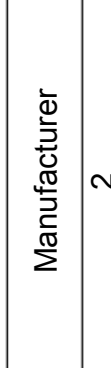 & 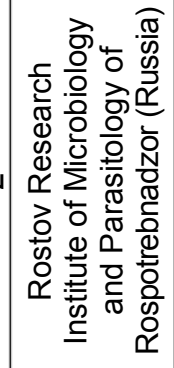 & 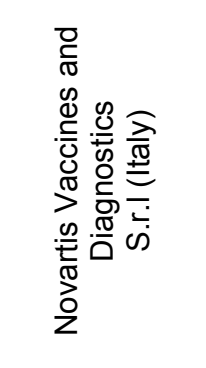 & 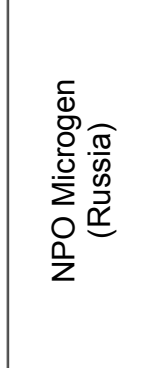 & 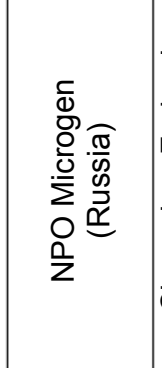 & 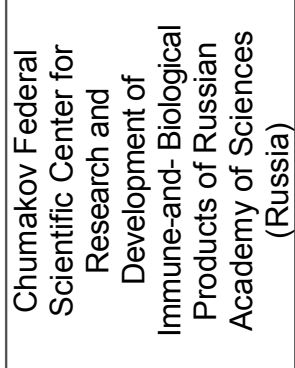 & 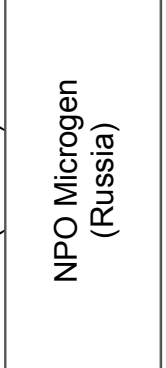 & 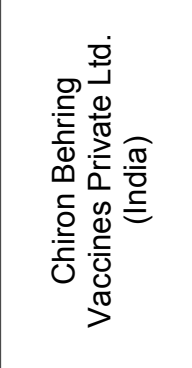 \\
\hline 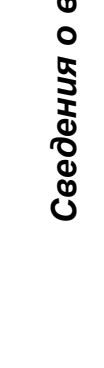 & 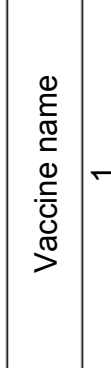 & 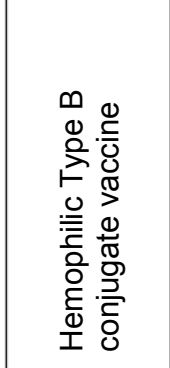 & 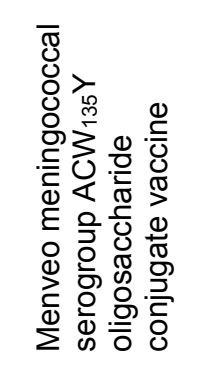 & 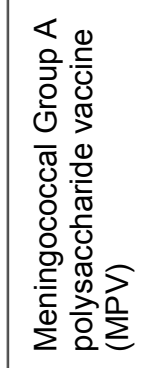 & 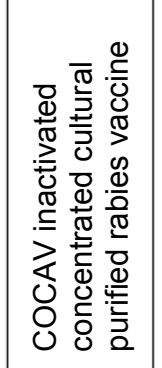 & 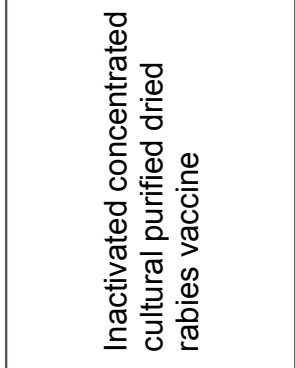 & 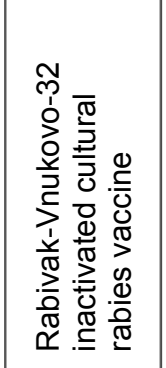 & 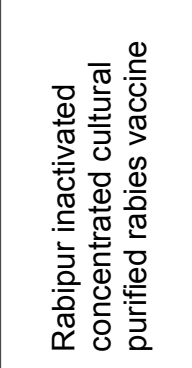 \\
\hline
\end{tabular}


Komissarov A.V., Bibikov D.N., Volokh O.A., et al. Lyophilisation of inactivated...

Комиссаров А.В., Бибиков Д.Н., Волох О.А. и др. Лиофилизация вакцин, не содержащих..

\begin{tabular}{|c|c|c|c|c|c|c|}
\hline & 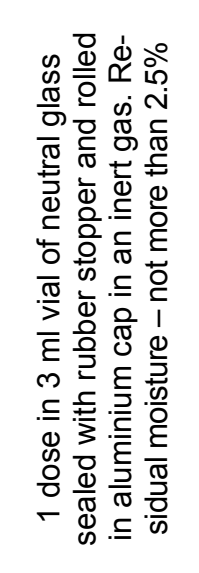 & 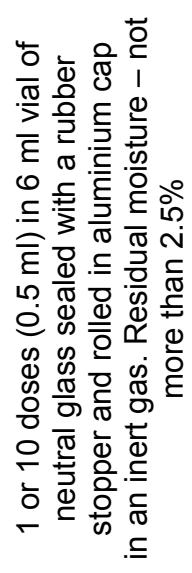 & 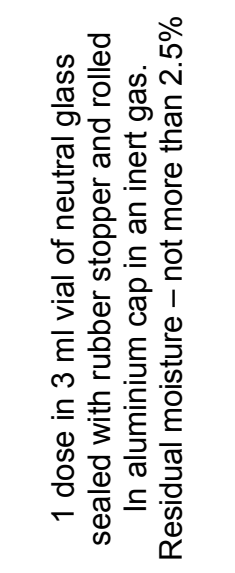 & 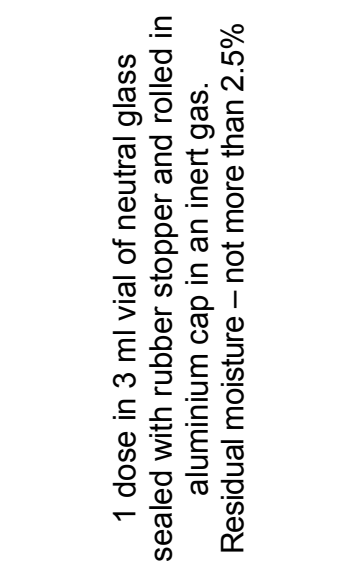 & 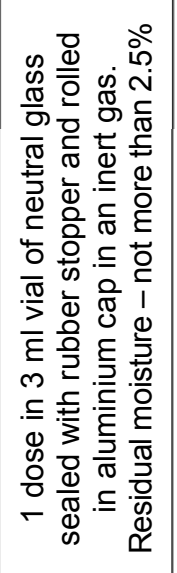 & 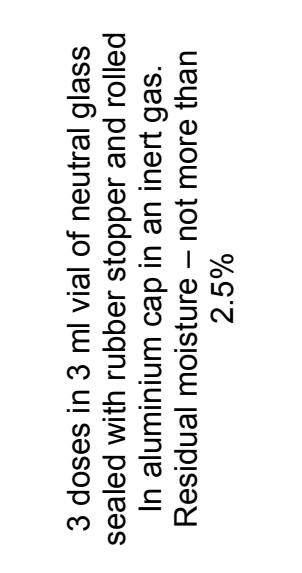 \\
\hline$\nabla$ & 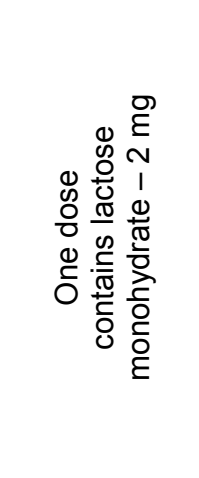 & 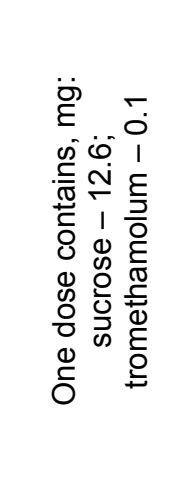 & 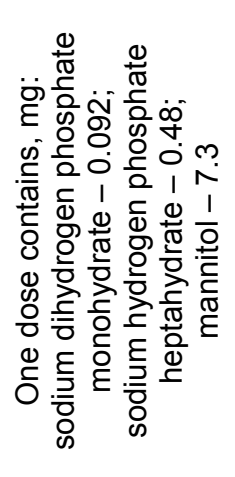 & 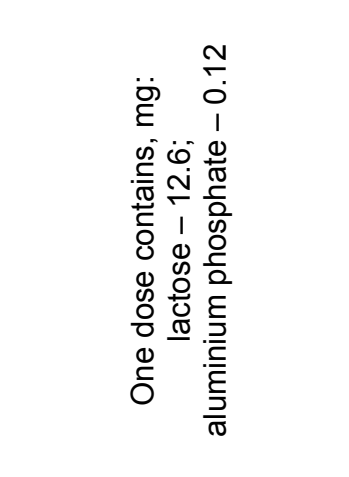 & 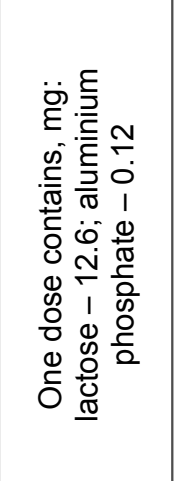 & 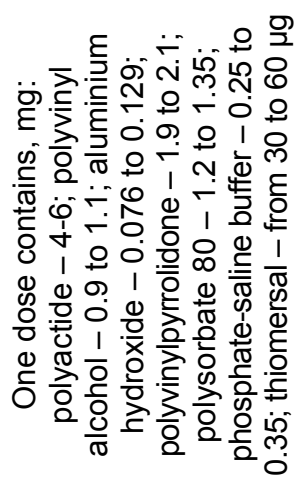 \\
\hline$m$ & 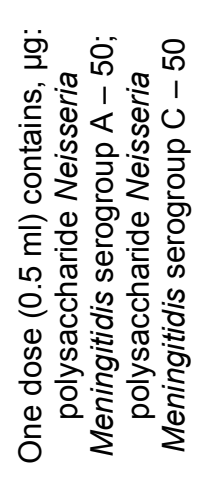 & 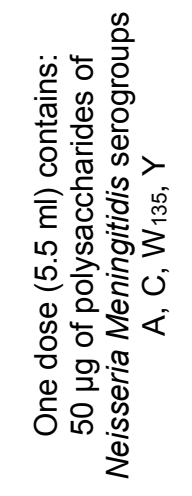 & 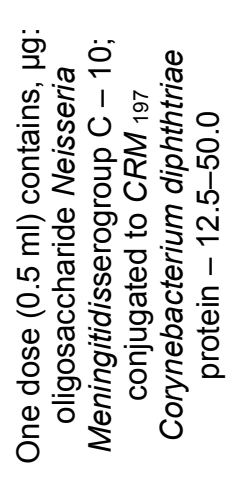 & 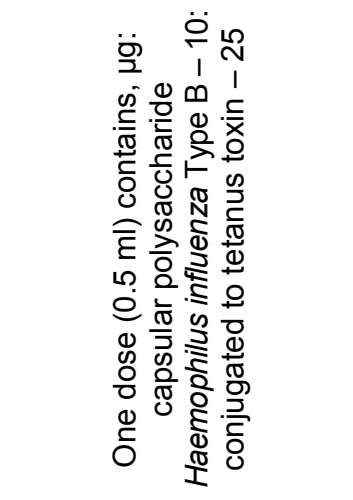 & 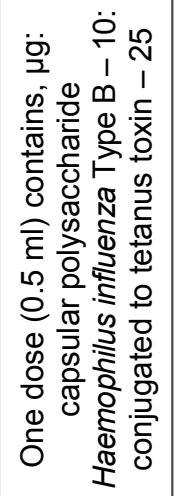 & 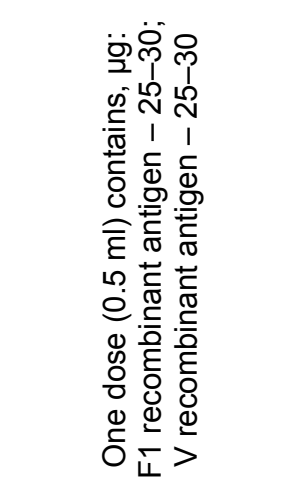 \\
\hline$\sim$ & 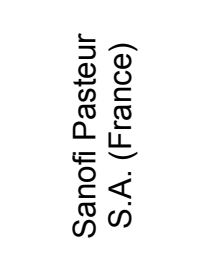 & 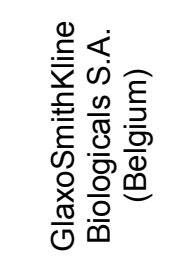 & 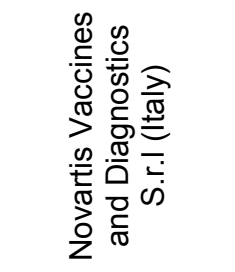 & 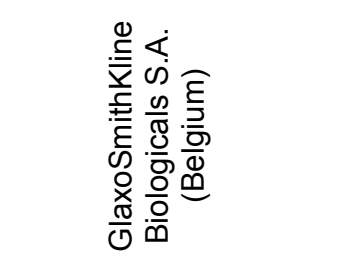 & 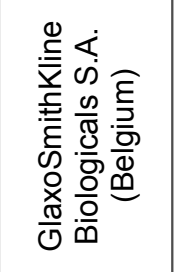 & 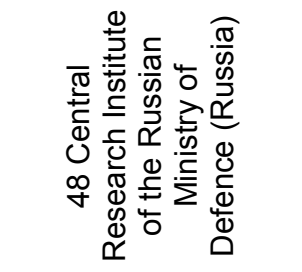 \\
\hline$r$ & 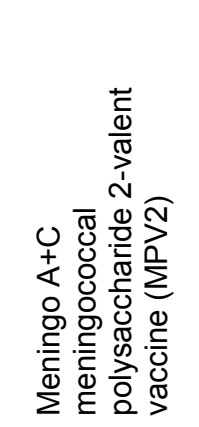 & 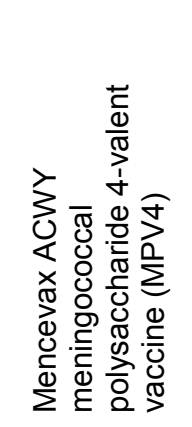 & 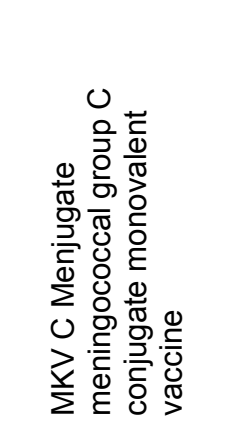 & 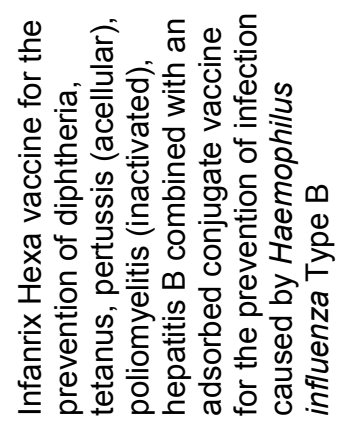 & 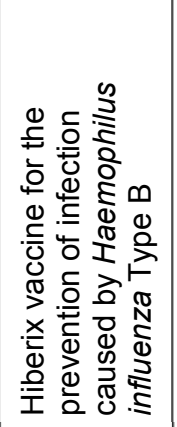 & 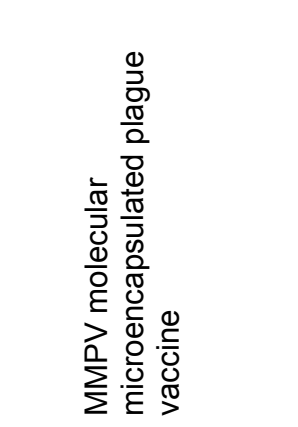 \\
\hline
\end{tabular}


Komissarov A.V., Bibikov D.N., Volokh O.A., et al. Lyophilisation of inactivated...

Комиссаров А.В., Бибиков Д.Н., Волох О.А. и др. Лиофилизация вакцин, не содержащих...

\begin{tabular}{|c|c|c|c|c|c|c|}
\hline & 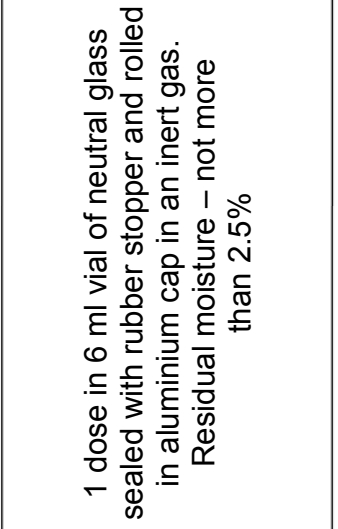 & 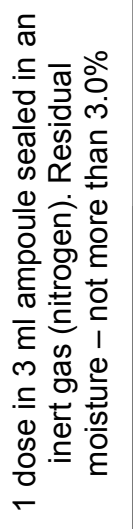 & 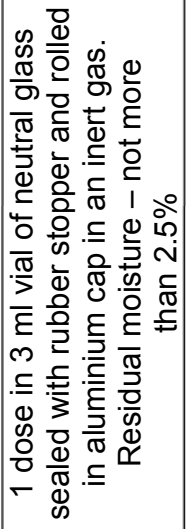 & 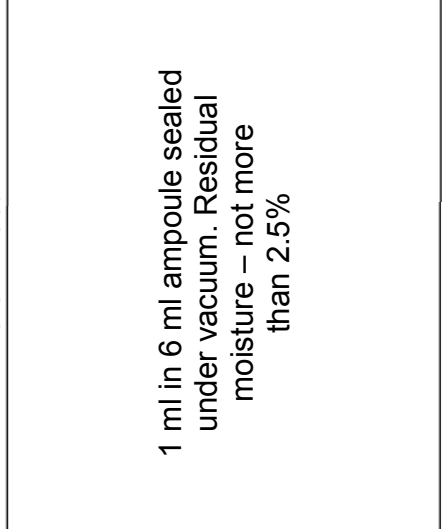 & 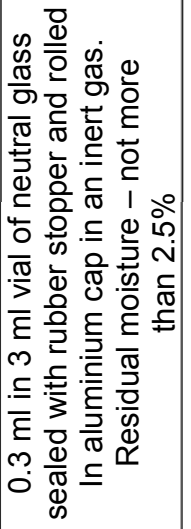 & 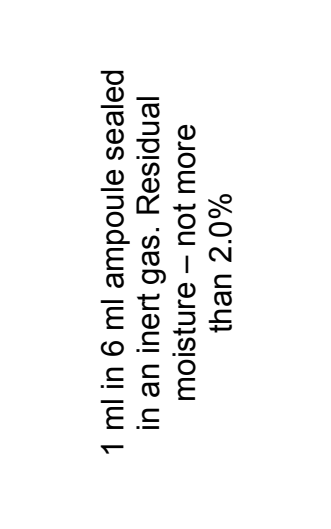 \\
\hline$\nabla$ & 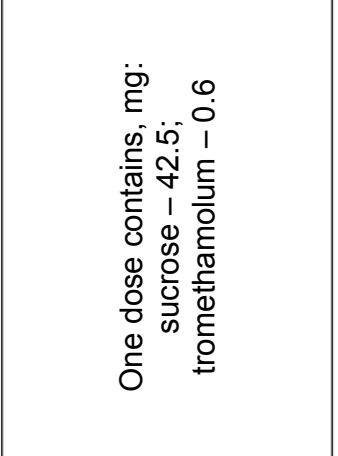 & 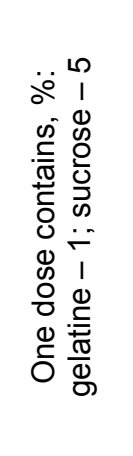 & 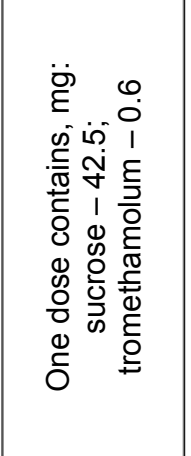 & 1 & 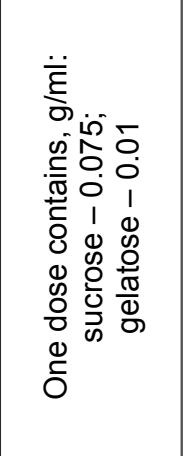 & 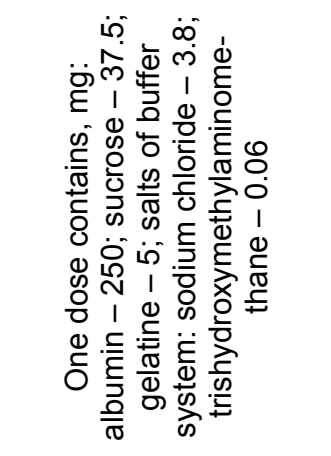 \\
\hline$m$ & 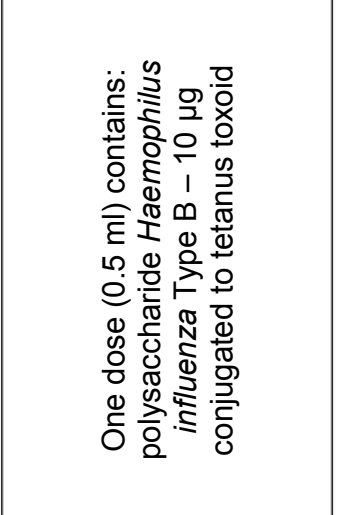 & 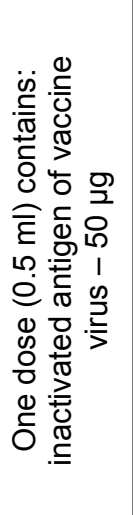 & 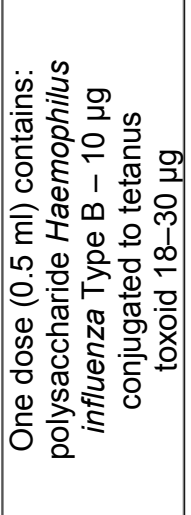 & 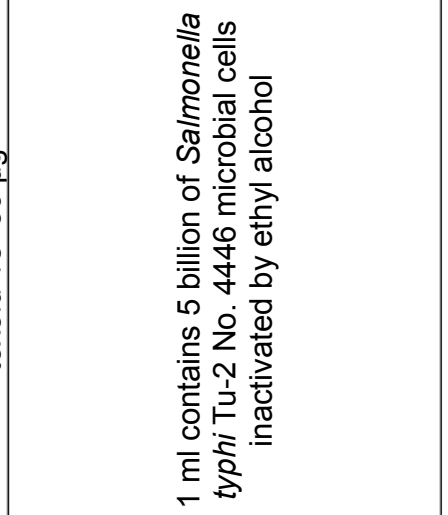 & 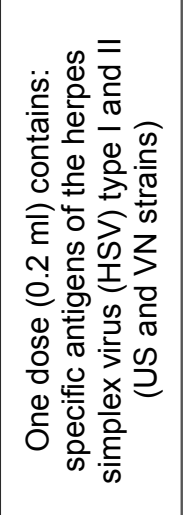 & 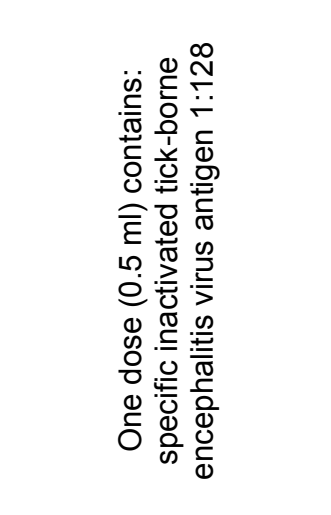 \\
\hline$\sim$ & 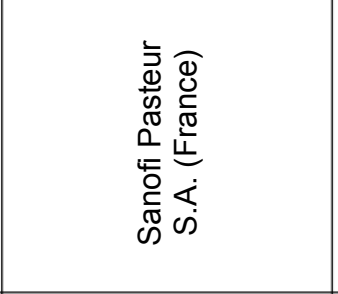 & 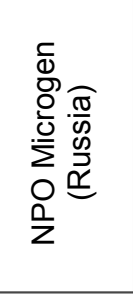 & 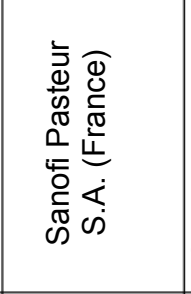 & 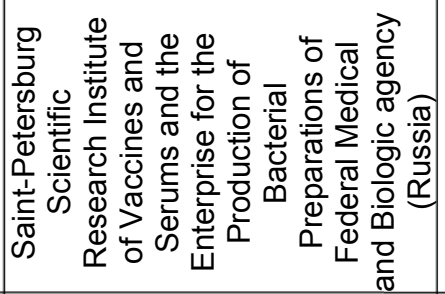 & 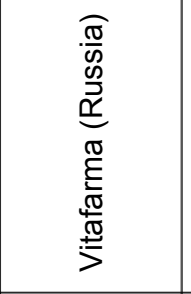 & 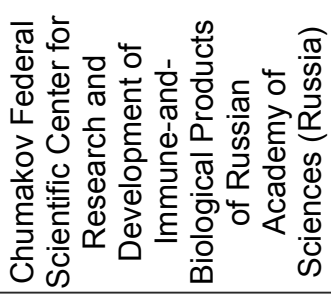 \\
\hline & 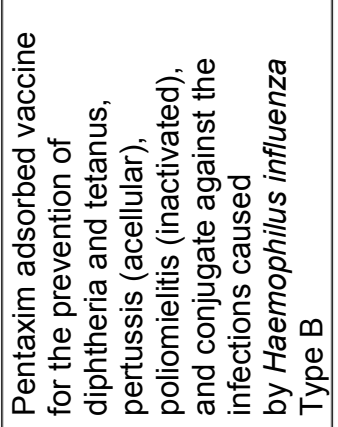 & 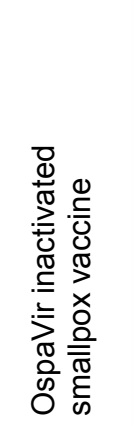 & 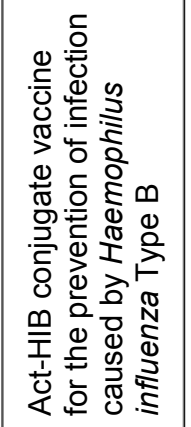 & 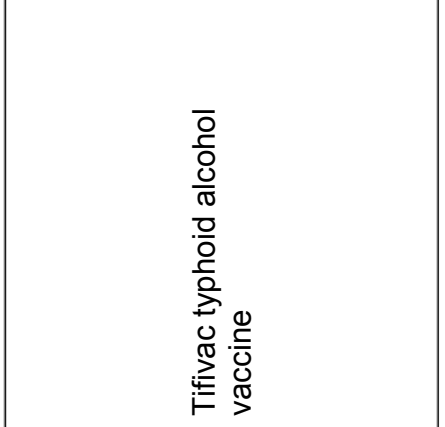 & 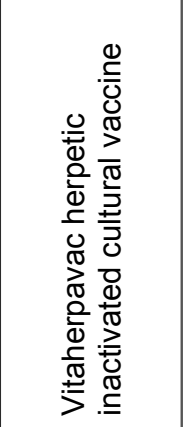 & 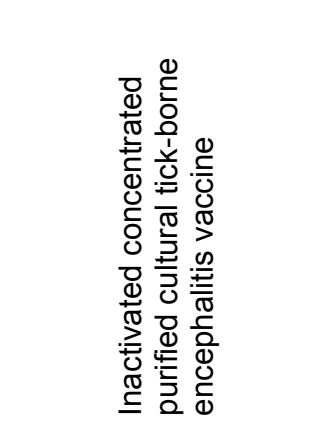 \\
\hline
\end{tabular}


Komissarov A.V., Bibikov D.N., Volokh O.A., et al. Lyophilisation of inactivated...

Комиссаров А.В., Бибиков Д.Н., Волох О.А. и др. Лиофилизация вакцин, не содержащих...

Table 2 Information about inactivated vaccines in the lyophilisate form
manufactured in the USA

Таблица 2

\section{Сведения о вакцинах, не содержащих живых микроорганизмов, в форме лиофилизата, производимых в США}

\begin{tabular}{|c|c|c|}
\hline Vaccine name & Manufacturer & Excipients \\
\hline $\begin{array}{l}\text { Pentacel vaccine against diphtheria, tetanus, } \\
\text { pertussis, poliomyelitis and invasive infections } \\
\text { caused by Haemophilus influenzae Type B }\end{array}$ & Sanofi & $\begin{array}{c}\text { Sucrose, Ammonium } \\
\text { Phosphate, PS80 } \\
\text { (Polysorbate-80 (Tween-80)) }\end{array}$ \\
\hline $\begin{array}{l}\text { Act-HIB conjugate vaccine to prevent the } \\
\text { infection caused by Haemophilus influenza Type B }\end{array}$ & Sanofi & Sucrose \\
\hline $\begin{array}{l}\text { Hiberix vaccine to prevent the infection caused } \\
\text { by Haemophilus influenza Type B }\end{array}$ & GSK & Lactose \\
\hline JE-Vax Japanese Encephalitis Vaccine & $\begin{array}{l}\text { The research foundation for } \\
\text { microbial diseases } \\
\text { of Osaka University }\end{array}$ & $\begin{array}{c}\text { Gelatine, PS80 } \\
\text { (Polysorbate-80 (Tween-80) }\end{array}$ \\
\hline $\begin{array}{l}\text { Menveo meningococcal serogroup } A_{C W} W_{135} Y \\
\text { oligosaccharide conjugate vaccine }\end{array}$ & $\begin{array}{l}\text { Novartis Vaccines and } \\
\text { Diagnostics, Inc. }\end{array}$ & $\begin{array}{l}\text { Potassium dihydrogen } \\
\text { phosphate, sucrose }\end{array}$ \\
\hline $\begin{array}{l}\text { Menomune-A/C/YM- } 135 \text { meningococcal } \\
\text { polysaccharide vaccine }\end{array}$ & Sanofi & Lactose \\
\hline Imovax rabies vaccine & Sanofi & Human Albumin Serum \\
\hline RabAvert rabies Vaccine & $\begin{array}{l}\text { Novartis Vaccines and } \\
\text { Diagnostics, Inc. }\end{array}$ & $\begin{array}{l}\text { Human Albumin Serum, } \\
\text { sodium glutamate }\end{array}$ \\
\hline
\end{tabular}

This is confirmed by the different excipient composition for the same preparation, e.g. the vaccine for the prevention of infection caused by Haemophilus influenza Type B produced by Hiberix by GlaxoSmithKline Biologicals S.A. uses $12.6 \mathrm{mg}$ of lactose as an excipient; Act-HIB by Sanofi Pasteur S.A. uses $42.5 \mathrm{mg}$ of sucrose and $0.6 \mathrm{mg}$ of tromethamolum, while the vaccine by the Rospotrebnadzor Rostov Research Institute of Microbiology and Parasitology in Russia uses between 20 and $30 \mathrm{mg}$ of sucrose (the compositions are stated per $0.5 \mathrm{ml}$ dose).

Since the technology used when manufacturing preparations is subject to commercial confidentiality, it is only possible to determine the features of vaccine production on the basis of the scientific and patent literature. However, it should be noted that for the vast majority of preparations indicated in the Table 1, technological aspects of production are not covered in detail in the available literature. As an example, we can cite the patent of the Russian Federation No. 2002115810, which discloses lyophilisation techniques used to produce the Vitaherpavac vaccine as follows: "The resulting suspension was lyophilised" [21].

The most complete information regarding the lyophilisation process is presented for two vaccines: the Ospavir inactivated dried smallpox vaccine and the molecular microencapsulated plague vaccine.

The technological lyophilisation methods for the
Ospavir vaccine are given as follows. The concentration of total protein in the inactivated viral fluid of the vaccine L-IVP strain is adjusted to $100 \mu \mathrm{g} / \mathrm{ml}$ with $0.007 \mathrm{M}$ Mcllvaine buffer solution with $\mathrm{pH}$ 7.2-7.4, while the following stabilisers are added: gelatine in a final concentration of $1 \%$ and sucrose in a final concentration of $5 \%$ in the form of gelatose $(10 \%)$ and sucrose $(50 \%)$ solutions. The preparation is dispensed into $0.5 \mathrm{ml}$ sterile ampoules, frozen to a final temperature of minus $50-55^{\circ} \mathrm{C}$ and lyophilised for 36 hours with the following parameters: initial shelf temperature - minus $40^{\circ} \mathrm{C}$; shelf heating rate $-5{ }^{\circ} \mathrm{C} / \mathrm{h}$; final product temperature $-25{ }^{\circ} \mathrm{C}$. The dried preparation is sealed in a flow of sterile nitrogen to reduce the residual oxygen concentration to less than $3 \%[22,23]$.

The technological approach used for the lyophilisation of the molecular microencapsulated plague vaccine is described as follows. The suspension of microencapsulated plague $\mathrm{F} 1$ and $\mathrm{V}$ recombinant antigens is dispensed into sterile penicillin vials in amounts of $3.0 \mathrm{ml}$ per vial. Freeze-drying is carried out using a Virtis freeze-dryer (USA) to a final moisture content of 3-6 wt. \%; here the stated typical drying time is $22-28$ hours. Glass vials containing the dried preparation are sealed with rubber stoppers and rolled in aluminium caps [24].

Additional information on the technological features of the vaccine lyophilisation or their specific components, which is absent in the SRMP, 
can be obtained from the following sources.

According to the order of the Ministry of Healthcare of the USSR No. 903 dated 16/11/1973, the "Microbe" Russian Research Anti-Plague Institute (RusRAPI), a cholera vaccine (cholerogentoxoid + O-antigen) was produced using a lyophilisate consisting of a mixture of cholerogen-toxoid and O-antigen obtained from formalin-inactivated supernatant of $01569-B \mathrm{~V}$. cholerae broth culture of the classic Inaba serovar biovar by means of isolation, purification, concentration and precipitation by ammonium sulphate ${ }^{4}$. This vaccine was distributed in ampoules having a capacity of 6,1 and $2 \mathrm{ml}$. The preparation was frozen in low-temperature refrigerators at a temperature of minus 40 to minus $50^{\circ} \mathrm{C}$ for $16 \pm 2$ hours. The ampoules containing the preparations were permitted to be stored at this temperature for a maximum of $70 \pm 2$ hours. The first stage of the drying process in lyophilisers employed the following parameters: temperature of heating shelves - minus $32 \pm 2{ }^{\circ} \mathrm{C}$; condenser temperature minus $75 \pm 5^{\circ} \mathrm{C}$. Shelf heating began at a preparation temperature from minus 40 to minus $45{ }^{\circ} \mathrm{C}$ and a vacuum of $5.6 \pm 3 \mathrm{kPa}$, but not earlier than 30 minutes after loading. The temperature of the preparation when dispensing into $1 \mathrm{ml}$ ampoules reached zero $17 \pm 1 \mathrm{~h}$ after the start of the drying process; when dispensing into $2 \mathrm{ml}$ ampoules, the corresponding time period was $23 \pm 1 \mathrm{~h}$. The maximum final temperature during the drying process was $25 \pm 1{ }^{\circ} \mathrm{C}$, while the minimum vacuum was $3.3 \pm 0.6 \mathrm{kPa}$. The maximum permitted loss of mass when drying the preparation was $2 \%$. In this case, it is worth noting that the lyophilisation of the preparation was carried out without the use of a drying medium and that the vaccine ampoules were sealed in atmospheric air. These technological methods are currently used in the production of cholera vaccines in tablet form at the stage of freeze-drying the immunogenic components [25].

Studies on the production of a lyophilised synthetic conjugate vaccine for the prevention of infections caused by Haemophilus influenzae Type B (HIB vaccines) were carried out by NPO Microgen (Perm Production Site) [26]. When developing the monovaccine, a synthetic polysaccharide (PRP) conjugated to a tetanus toxoid (active pharmaceutical ingredient) manufactured by the Heber Biotec Center of Genetic Engineering and Biotechnology (Cuba) was used. The lyophilisation mode developed for a single dose $(0.5 \mathrm{ml})$ of the preparation in ampoules having a capacity of $2 \mathrm{~cm}^{3}$, with $25 \%$

\footnotetext{
${ }^{4}$ Джапаридзе М.Н., Наумов А.В., Елисеев Ю.Ю. Холерные химические вакцины института «Микроб» (принципы конструирования, подбора штаммов, биотехнологии) // Иммунохимия и специфическая профилактика особо опасных инфекций: сб. тезисов Российской науч. конф. (Саратов, 21-23 сентября 1993 г.). Саратов: Изд-во ВНИПИ «Микроб», 1993. С. 181-182.
}

of the volume at a column height of $9 \pm 1 \mathrm{~mm}$, was as follows: freezing the preparation at minus $35 \pm 5{ }^{\circ} \mathrm{C}$ and maintaining at this temperature for not less than 8 hours; carrying out the lyophilisation stage at a vacuum of at least $16 \mathrm{~Pa}$, with a maximum condenser temperature of minus $50{ }^{\circ} \mathrm{C}$ drying of the preparation at positive temperatures for 15 hours. The total duration of the sublimation process was $30 \pm 4$ hours, while the final temperature of the preparation was $33 \pm 4{ }^{\circ} \mathrm{C}$. The developed lyophilisation mode and selected sucrose cryoprotectant concentration $(8.5 \%)$, as well as the amount of substances in the buffer system (sodium dihydrogen phosphate $-0.16 \mathrm{mg}$; disodium hydrogen phosphate $-0.5 \mathrm{mg}$ ) was sufficient to ensure the preservation of the necessary technological characteristics of HIB vaccine lyophilised form. After drying, the ampoules were sealed in an atmosphere of sterile air. All the preparation samples consisted of a uniform, amorphous mass of white colour easily soluble in water for injection purposes. In all of the studied samples, the weight loss on drying (residual moisture) did not exceed $3 \%$. Subsequent trials have shown that the specific properties of the vaccine are not degraded as compared to commercial preparations. Stability studies showed that the quality of the vaccine was maintained for 3 years of storage at a temperature of 2 to $8^{\circ} \mathrm{C}$

The studies conducted at the "Microbe" facility led to the development of a prototype lyophilisate anthrax chemical vaccine on the basis of the following purified antigens: rPA recombinant protective antigen, EA1 S-layer protein and CpG-2006 cytosine guanine oligodeoxynucleotide adjuvant [27]. Purified antigens, adjuvant and preservative (contents in $\mu \mathrm{g}$ per $1 \mathrm{~cm}^{3}$ : rPA - 100; EA1 protein - 50; CpG 2006 - 0.5; formaldehyde $0.002 \%$ ) were mixed with sterile stabiliser solutions in the required ratio with $2.5 \mathrm{~cm}^{3}$ of the preparation dispensed in $10.0 \mathrm{~cm}^{3}$ vials. At the end of the packaging process, the vials containing the preparation were placed on the shelves of an Epsilon-2-6D (Martin Christ, Germany) freeze-dryer; next, the temperature of the material was reduced to minus $40{ }^{\circ} \mathrm{C}$ and maintained for 2 hours. A residual pressure of not more than $30 \mathrm{~Pa}$ was then created in the drying unit and the sublimation process took place with increasing temperature of the material up to $5^{\circ} \mathrm{C}$ at a rate of no more than $3^{\circ} \mathrm{C} / \mathrm{h}$. Upon reaching the indicated value, the rate of temperature increase was elevated to $10{ }^{\circ} \mathrm{C} / \mathrm{h}$. After reaching $28^{\circ} \mathrm{C}$ in the material, the drying was carried out for 7 hours. Then the vials were sealed in air atmosphere and clogged with aluminium caps. The preparations were stored at $4{ }^{\circ} \mathrm{C}$. Various cryoprotectants were used in the experiments: $10 \%$ sucrose, $1 \%$ sucrose $+3 \%$ glycine, $1 \%$ maltose $+3 \%$ glycine. When using $10 \%$ sucrose, the formation of a vitreous mass was observed. This can be explained by the absence of the com- 
ponents forming the crystalline structure in the composition of the frozen product.

As a result of two other stabilisation options, the lyophilised preparation consisted of a porous mass in the form of a milky white tablet capable of complete dissolution in a $0.9 \%$ sodium chloride solution in less than a minute, forming a clear, colourless liquid without impurities or flakes. Upon further study of the specific properties of the prototype vaccine, the advantages of using $1 \%$ sucrose $+3 \%$ glycine drying medium were revealed with the vaccine prototype meeting the stated requirements for immunobiological preparations [28].

Data on a method for obtaining a dried combined anthrax vaccine including both living microorganisms and antigens as immunogens are given in [29]. The dry combined anthrax vaccine consists of the following components: sorbed protective antigen obtained from Bacillus anthracis 55/5 strain; the spores of Bacillus anthracis STI-1strain; sucrose; aluminium hydroxide gel. One vaccination dose of the vaccine (in the volume of $0.5 \mathrm{~cm}^{3}$ ) contains 40-60 million spores of STI-1 strain, 30-40 ID 50 of protective antigen; not more than $0.2 \mathrm{mg}$ of total nitrogen; not more than $2.5 \mathrm{mg}$ of aluminium oxide; not more than $0.0005 \%$ formaldehyde and $18-22 \mathrm{mg}$ of sucrose. The authors claim that the methods used for lyophilisation can increase the shelf life of the vaccine up to 4 years and extend the storage temperature regime to plus $25^{\circ} \mathrm{C}$ for a month after the vaccine is delivered to the consumer. An additional method for preparing a dry combination anthrax vaccine is described as follows. The spore suspension of Bacillus anthracis STI-1 strain is diluted with sterile saline to a concentration of 0.8-1.2 billion spores $/ \mathrm{cm}^{-3}$. The resulting suspension is mixed with a sterile $40 \%$ sucrose solution in a volume ratio of $1: 1$ and stirred for 15-20 minutes. The concentrate of sorbed protective antigen is diluted with sterile saline to a content of $400 \mathrm{ID}_{50} / \mathrm{cm}^{-3}$. Equal volumes of the prepared components are combined and thoroughly mixed. The prepared liquid semi-finished product of the combination vaccine should contain 200-300 million spores $/ \mathrm{cm}^{-3}$ and $180-220 \mathrm{ID}_{50} / \mathrm{cm}^{-3}$ of the protective antigen. $2 \mathrm{~cm}^{3}$ (10 vaccination doses) of the prepared semi-finished vaccine is dispensed into ampoules with a capacity of $6 \mathrm{~cm}^{3}$ or vials of $10 \mathrm{~cm}^{3}$. Lyophilic drying of the vaccine is carried out in chamber dry-freezers providing the following mode: suspension freezing temperature - minus $35-40{ }^{\circ} \mathrm{C}$; holding time - 3-4 hours; vacuum in the sublimator 20-25 Pa. The final drying of the material takes place at a temperature of $30-32{ }^{\circ} \mathrm{C}$ for $10-12$ hours.

A kit developed by Novartis International AG described in [30] contains a $0.5 \mathrm{ml}$ lyophilised antigen composition comprising an immunogen to induce an immune response against Neisseria meningitidis of serological group $B$. The authors showed that the lyophilisation of the antigen to a residual moisture content in the range of $1.1 \%$ using differ- ent drying medium compositions of $2 \%$ mannitol and $3 \%$ sucrose, $5 \%$ sucrose, $4.5 \%$ mannitol and $1.5 \%$ sucrose allows the stability of the preparation to be maintained during storage.

Scientists from the Netherlands have developed a technology for producing a lyophilisate of a subunit influenza vaccine (A/Panama/2007/99, H3N2) based on a monovalent vaccine manufactured by Solvay Pharmaceuticals (Netherlands) for intranasal aerosol vaccination. The studies have shown that this type of vaccination gives a better immune response in mice as compared to the liquid form of the vaccine. The vaccine powder was prepared as follows. A solution containing $275 \mu \mathrm{g} / \mathrm{ml}$ of antigen and $5.5 \% \mathrm{w} / \mathrm{v}$ of inulin (D-fructose polymer) was frozen in nitrogen and then placed in an EpsiIon 2-4 (Germany) freeze-dryer. The drying took place at a vacuum of 0.220 mbar with a condenser temperature of minus $85^{\circ} \mathrm{C}$. The shelf temperature was increasing gradually from minus 40 to $5{ }^{\circ} \mathrm{C}$ over 32 hours. Further, the vacuum pressure was reduced to $0.055 \mathrm{mbar}$, the shelf temperature was gradually increased to $20{ }^{\circ} \mathrm{C}$ over a period of 11 hours. The obtained lyophilisate was stored under vacuum prior to the start of the experiments [31].

The same scientists conducted the studies on the vaccine preparation in vials [32]. In the course of the research, the effect of various carbohydrates, buffer solutions and freezing rate on the antigen persistence during lyophilisation was studied. The preference of quick freezing, as well as the using of HEPES buffer (4-(2-hydroxyethyl)-1-piperazineethanesulfonic acid) and carbohydrates (trehalose, inulin and dextran) as cryo- and lyoprotectants was shown. It was revealed that a dried subunit vaccine does not lose immunogenicity, while storage under vacuum allows the properties of the preparation to be preserved. $4 \mathrm{ml}$ vials containing $0.5 \mathrm{ml}$ of the preparation $(360 \mu \mathrm{g} / \mathrm{ml}$ of antigen and $1.7 \% \mathrm{w} / \mathrm{v}$ of carbohydrates) were frozen for 24 hours at minus $20{ }^{\circ} \mathrm{C}$ or in liquid nitrogen for 5-10 minutes. Although lyophilisation was carried out using the same type of equipment as in the previous example, the process parameters were different. The drying proceeded under a vacuum of $0.220 \mathrm{mbar}$ with a condenser temperature of minus $55{ }^{\circ} \mathrm{C}$. The shelf temperature was increased gradually from minus 35 to $5^{\circ} \mathrm{C}$ over 24 hours. Next, the vacuum pressure was reduced to 0.055 mbar and the shelf temperature was gradually increased to $20{ }^{\circ} \mathrm{C}$ over a period of 24 hours. Further studies have shown the possibility of using only one stabiliser (inulin) for vaccine lyophilisation [33].

American scientists have shown that complete protection against inhalation anthrax can be achieved by intranasal delivery of the powder preparation of the Bacillus anthracis [34] recombinant protective antigen. The optimum $\mathrm{pH}$ for preserving the properties of protective antigen during lyophilisation was experimentally found to vary from 6 to 8 , which was ensured by the use of a HEPES 
buffer. The use of the following biopharmaceutical composition is justified: antigen $(0.5 \mathrm{mg} / \mathrm{ml})$, trehalose as a stabiliser $(0.99 \mathrm{mg} / \mathrm{ml})$ and $\mathrm{CpG}$ adjuvant $(0.5 \mathrm{mg} / \mathrm{ml})$. Freezing was carried out in liquid nitrogen. Vials placed on shelves of a freeze-dryer were pre-cooled to minus $40^{\circ} \mathrm{C}$. Primary drying was carried out for 16 hours at a shelf temperature of minus $10^{\circ} \mathrm{C}$; the final drying was carried out at $20^{\circ} \mathrm{C}$. The preparation was sealed in nitrogen medium.

Polish scientists have developed a technology for lyophilisation of surface HBV antigen for the oral hepatitis B vaccine [35]. The authors propose feasible technological methods providing $100 \%$ preservation of immunogenic properties. Two methods of freezing - fast and slow - were tested. Fast freezing was carried out by immersing the material in liquid nitrogen. Slow freezing was carried out in a freeze-dryer from ambient temperature to minus $35^{\circ} \mathrm{C}$ at a rate of $2{ }^{\circ} \mathrm{C} / \mathrm{min}$. The latter method was shown to give improved results. Among the applied protectors (sucrose, glucose, mannitol, glycine and glycerin), the best results were obtained with the use of sucrose. The optimal parameters of the lyophilisation process in pallets with a preparation height of $5 \mathrm{~mm}$ were revealed as follows: residual pressure $0.15-0.2 \mathrm{mbar}$, shelf temperature profile $-20^{\circ} \mathrm{C} / 22 \mathrm{~h}$, then $22{ }^{\circ} \mathrm{C} / 2 \mathrm{~h}$.

A hepatitis $B$ vaccine and its lyophilisation technology is described in a US patent [36]. $1 \mathrm{ml}$ of a preparation containing HBV surface antigen adsorbed on aluminium hydroxide gel $(40 \mu \mathrm{g} / \mathrm{ml}$ of protein), lactose $(10.0 \mathrm{w} / \mathrm{v} \%)$, glycine $(1.0 \mathrm{w} / \mathrm{v} \%)$, gelatine $(0.05 \mathrm{w} / \mathrm{v} \%)$, thiomersal $(0.005 \mathrm{w} / \mathrm{v} \%)$ and phosphate buffer ( $\mathrm{pH}$ 6.0) was dispensed into $2 \mathrm{ml}$ vials and frozen at a temperature of minus $50{ }^{\circ} \mathrm{C}$ for 6 hours. Lyophilisation was carried out at a residual pressure of 0.04 Torr, maintaining a shelf temperature at $5{ }^{\circ} \mathrm{C}$ for 15 hours and then $30{ }^{\circ} \mathrm{C}$ for 8 hours. The applied drying media and technological parameters of lyophilisation allowed the properties of the vaccine to be preserved.

A lyophilisation technology for an inactivated poliomyelitis vaccine has been developed in the Netherlands. In the course of the research, various components and combinations of the drying medium were used: monosodium glutamate, sucrose, sorbitol, trehalose, inositol, ovalbumin, mannitol, glycine, magnesium chloride and lithium chloride. The final experimentally-validated version of the drying medium included $10 \%(\mathrm{w} / \mathrm{v})$ of sorbitol, $8.5 \%(\mathrm{w} / \mathrm{v})$ of magnesium chloride and $8.5 \%(\mathrm{w} / \mathrm{v})$ of sodium glutamate. Lyophilisation procedures were as follows: $0.2 \mathrm{ml}$ of the product was dispensed into $2 \mathrm{ml}$ vials, frozen to minus $50{ }^{\circ} \mathrm{C}$ on the shelves of a freeze-dryer with a cooling rate of $1^{\circ} \mathrm{C} / \mathrm{min}$. Subsequently, the preparation was main tained at the indicated temperature for 2 hours, then the shelf temperature was increased to minus $45{ }^{\circ} \mathrm{C}$ with a heating rate of $0.2{ }^{\circ} \mathrm{C} / \mathrm{h}$, after which it was kept for 3 hours at a vacuum of
0.045 mbar. The authors referred to this stage as primary drying. Secondary drying was carried out with a further increase in shelf temperature at a rate of $0.02{ }^{\circ} \mathrm{C} / \mathrm{min}$ to $25^{\circ} \mathrm{C}$ under vacuum not exceeding $0.01 \mathrm{mbar}$ and holding for 24 hours. At the end of the process, the vials were sealed under vacuum [37].

Recent studies carried out in the USA were aimed at developing an Ebola fever vaccine lyophilisate [38]. The biopharmaceutical composition was as follows: $0.1 \mathrm{mg} / \mathrm{ml}$ of Ebola virus glycoprotein, $10 \mathrm{mM}$ of ammonium acetate ( $\mathrm{pH} 7.0)$, $9.5 \%(\mathrm{w} / \mathrm{v})$ of trehalose and $0.5 \mathrm{mg} / \mathrm{ml}$ of aluminium hydroxide. $1 \mathrm{ml}$ of the preparation was dispensed into $3 \mathrm{ml}$ vials and frozen to minus $40{ }^{\circ} \mathrm{C}$ at a rate of $0.5^{\circ} \mathrm{C} / \mathrm{min}$ on the shelves of the lyophilisation unit and kept at this temperature for $1 \mathrm{~h}$. The drying process was carried out at a vacuum of $8 \mathrm{~Pa}$. In order to start the sublimation process, the shelf temperature was increased to minus $20^{\circ} \mathrm{C}$ at a rate of $1^{\circ} \mathrm{C} / \mathrm{min}$ and maintained at this temperature for 20 hours. Desorption was carried out according to the following scheme: the shelf temperature was increased to $0{ }^{\circ} \mathrm{C}$ at a rate of $0.2{ }^{\circ} \mathrm{C} / \mathrm{min}$, followed by an increase to $30{ }^{\circ} \mathrm{C}$ at a rate of $0.5{ }^{\circ} \mathrm{C} / \mathrm{min}$. The preparation was then kept at $30{ }^{\circ} \mathrm{C}$ for 5 hours. After drying, the vials were sealed in nitrogen. It should be noted that these technological methods had previously been used for lyophilisation of the anthrax vaccine, in which process the recombinant protective antigen [39] and human papillomavirus vaccine [40] served as immunogens.

An international patent [41] discloses, among other things, the technological features of lyophilisation of the polyvalent polysaccharide-protein conjugate vaccine against meningococcal infection. Men $\mathrm{A}, \mathrm{C}, \mathrm{Y}, \mathrm{W}, \mathrm{X}$ capsular polysaccharides conjugated to a tetanus toxoid carrier protein were used as immunogens of the vaccine against Neisseria meningitidis of $\mathrm{A}, \mathrm{C}, \mathrm{Y}, \mathrm{W}$ and $\mathrm{X}$ serogroups. The concentration of capsular polysaccharides was $10-20 \mathrm{ml} / \mathrm{ml}$. Sucrose (1-3\%), maltose (1-4\%), lactose $(1-4 \%)$, mannitol $(1-4 \%)$ and glycine $(20 \mathrm{mmol})$ were used as cryo- and lyoprotectants. A HEPES buffer solution was used to stabilise $\mathrm{pH}$ at 6.5-7.5. $0.5 \mathrm{ml}$ of the preparation was dispensed. The lyophilisation technological scheme was developed as follows:

- freezing, consisting of 3 steps: keeping in the freeze-dryer chamber for 60 minutes at a temperature of $4{ }^{\circ} \mathrm{C}$; freezing to minus $48{ }^{\circ} \mathrm{C}$ for $250 \mathrm{~min}$; keeping at this temperature for 360 minutes;

- primary drying, which includes 6 steps: minus $28^{\circ} \mathrm{C}-240$ min; minus $20{ }^{\circ} \mathrm{C}-780$ min; minus $10{ }^{\circ} \mathrm{C}-60 \mathrm{~min} ; 10^{\circ} \mathrm{C}-120 \mathrm{~min} ; 25^{\circ} \mathrm{C}-60 \mathrm{~min}$; $30{ }^{\circ} \mathrm{C}-30 \mathrm{~min}$;

- secondary drying, in which the preparation is maintained at a temperature of $30{ }^{\circ} \mathrm{C}$ for 500 minutes.

It should be noted that the vacuum during the whole process was maintained at the level of 50 mTorr. Feasible technological solutions are 
described which allow an immunogenic preparation to be obtained having a residual moisture content of less than $3 \%$.

Human papillomavirus vaccine compositions are described in the US Patent of 2017 [42]. The authors proposed 18 combinations of the vaccine with variation of excipient components (sucrose, mannitol and glycine) both in qualitative and quantitative terms. The lyophilisation procedure was described in detail. $0.6 \mathrm{ml}$ of vaccine samples were dispensed into $3 \mathrm{ml}$ glass vials, frozen on the lyophiliser shelf to minus $50^{\circ} \mathrm{C}$ and kept for 1 hour. Next, an "annealing" procedure was carried out, which consisted in heating the preparation to minus $20{ }^{\circ} \mathrm{C}$ (at a rate of $0.5{ }^{\circ} \mathrm{C} / \mathrm{min}$ ), followed by cooling to minus $50{ }^{\circ} \mathrm{C}$ (at a rate of $0.5^{\circ} \mathrm{C} / \mathrm{min}$ ) and maintaining this temperature for 2.5 hours. Primary drying was carried out for 48 hours by heating the shelf to minus $20{ }^{\circ} \mathrm{C}$ (at a rate of $1{ }^{\circ} \mathrm{C} / \mathrm{min}$ ). Secondary drying was carried out by heating the shelf to $10{ }^{\circ} \mathrm{C}$ (at a rate of $0.5^{\circ} \mathrm{C} / \mathrm{min}$ ) and maintaining this temperature for 4 hours. A vacuum of 100 mTorr was used throughout. Following lyophilisation, the vials were sealed in nitrogen.

Chinese researchers have announced a lyophilised inactivated vaccine against Japanese encephalitis [43]. The preparation contains maltose (10 to $50 \% \mathrm{w} / \mathrm{w})$, lactose (10 to $50 \% \mathrm{w} / \mathrm{w})$, mannitol (5 to $50 \% \mathrm{w} / \mathrm{w}$ ), $0.01 \mathrm{M}$ phosphate buffer at a final concentration of encephalitis virus antigen $3 \mathrm{EU} / \mathrm{ml}$. The dosage in primary packaging is $0.5 \mathrm{ml}$. The following lyophilisation parameters were used: freezing on the shelves of a freeze-dryer at a temperature of minus $45{ }^{\circ} \mathrm{C}$ for 2 hours, drying at a vacuum of $0.02 \mathrm{MPa}$ by increasing the shelf temperature to $30^{\circ} \mathrm{C}$ with a rate of $2{ }^{\circ} \mathrm{C} / \mathrm{h}$. The authors declare the preservation of antigenic activity for 5 years.

An international patent [44] describes the technology of anthrax vaccine lyophilisate production. The vaccine contains $200 \mathrm{pg} / \mathrm{ml}$ of recombinant anthrax protective antigen, $2 \mathrm{mg} / \mathrm{ml}$ of CpG1018, 5\% of trehalose, $5.25 \mathrm{mmol}$ of phosphate, $0.39 \%$ of so- dium chloride, $0.02 \%$ of Tween 20 , and $0.26 \% \mathrm{w} / \mathrm{v}$ of alhydrogel. Unfortunately, the patent does not indicate the volume of the lyophilised substance. Lyophilisation was carried out using a Martin Christ freeze-dryer in the following mode: freezing on the shelves of a freeze-dryer at a temperature of minus $40{ }^{\circ} \mathrm{C}$ for 180 minutes, heating the shelf to minus $30{ }^{\circ} \mathrm{C}$ for 45 minutes, drying at this temperature for 2400 minutes, heating the shelf to $20{ }^{\circ} \mathrm{C}$ for $500 \mathrm{~min}$, then drying at a given temperature for $480 \mathrm{~min}$. The vacuum was $113 \mathrm{mTorr}$. Following lyophilisation, the vials were sealed under vacuum. The residual moisture was less than $3 \%$. In the patent, it is stated that the vaccine retains its immunogenic properties after lyophilisation.

A Canadian patent describes a lyophilised subunit vaccine against herpes simplex virus [45]. The composition of the preparation ( $\mathrm{pH} 7.2-7.4)$ : purified herpes simplex virus glycoprotein up to $30 \mathrm{~g} / \mathrm{ml}$; lactose - $10 \mathrm{w} / \mathrm{v} \%$; sodium glutamate $-0.4 \mathrm{w} / \mathrm{v} \%$; arginine $-0.4 \mathrm{w} / \mathrm{v} \%$; gelatine $-0.8 \mathrm{w} / \mathrm{v} \%$; thiomersal $0.005 \mathrm{w} / \mathrm{v} \% .1 \mathrm{ml}$ of the solution was dispensed and frozen at minus $50{ }^{\circ} \mathrm{C}$ for 6 hours. Primary drying was carried out for 15 hours at a shelf temperature of $5{ }^{\circ} \mathrm{C}$; secondary - at $30^{\circ} \mathrm{C}$ for 8 hours. The vacuum was 0.05 Torr.

\section{CONCLUSION}

The review of the literature on the aspects of vaccine lyophilisation not containing live microorganisms revealed the expediency of sealing the primary packaging of preparations in an oxygenfree medium (under vacuum or filled with an inert gas). It has been shown that the preservation of the vaccine properties during freeze-drying is influenced by a number of parameters, the most significant of which include the rate of freezing and the temperature-time parameters of the processes of primary drying and desorption. It has been established that the preservation of the target properties of lyophilised preparations is dependent on selecting the correct qualitative and quantitative characteristics of the drying medium.

\section{REFERENCES}

1. Plotkin S.A., Springer N.Y. History of Vaccine Development. New York: Springer, 2011, 364 p. DOI: 10.1007/978-1-4419-1339-5_6

2. Salmon D.E., Smith T. On a new method of producing immunity from contagious diseases. Proceedings of the Biological Society of Washington. 1884-1886, vol. 3, pp. 29-33.

3. Varshney D., Singh M. Lyophilized Biologics and Vaccines. Modality-Based Approaches. New York: Springer, 2015, 401 p. DOI: 10.1007/978-14939-2383-0

4. Pikal M.J. Freeze-drying of proteins. Part I: process design. BioPharm. 1990, vol. 3, pp. 18-28.

5. Gusarov D.A. Freeze-drying of biopharmaceutical proteins (mini-review). Biofarmatsevticheskii zhurnal. 2010, vol. 2, no. 5, pp. 3-7. (In Russian)
6. Wang W. Lyophilization and development of solid protein pharmaceuticals. International journal of pharmaceutics. 2000 , vol. 203, issue 1-2, pp. 1-60. https://doi.org/10.1016/S0378-5173(00)00423-3

7. Pikal M.J., Rambhatla S., Ramot R. The Impact of the Freezing Stage in Lyophilization: Effects of the Ice Nucleation Temperature on Process Design and Product Quality. Journal of the American Pharmacists Association. 2002, vol. 5, pp. 48-53.

8. Tang X., Pikal M.J. Design of Freeze-Drying Processes for Pharmaceuticals: Practical Advice. Pharmaceutical Research. 2004, vol. 21, issue 2, pp. 191-200.

9. Franks F., Auffret T. Freeze-Drying of Pharmaceuticals and Biopharmaceuticals. Principles and Practice. Cambridge, UK: RSCPublishing, 2007, 206 p. 
10. Searles J.A., Carpenter J.F., Randolph T.W. The ice nucleation temperature determines the primary drying rate of lyophilization for samples frozen on a temperature-controlled shelf. Journal of Pharmaceutical Sciences. 2001, vol. 90, issue 7, pp. 860-871. https://doi.org/10.1002/jps.1039

11. Cochran T., Nail S.L. Ice nucleation temperature influences recovery of activity of a model protein after freeze drying. Journal of Pharmaceutical Sciences. 2009, vol. 98, issue 9, pp. 3495-3498. DOI: $10.1002 / j p s .21815$

12. Heller M.C., Carpenter J.F., Randolph T.W. Protein formulation and lyophilization cycle design: prevention of damage due to freezeconcentration induced phase separation. Biotechnology and Bioengineering. 1999, vol. 63, issue 2, pp. 166-174. DOI: 10.1002/(SICl)1097-0290(19990420)63:2<166: :AID-BIT5>3.0.CO;2-H

13. Franks F. Freeze-drying of bioproducts: putting principles into practice. European Journal of Pharmaceutics and Biopharmaceutics. 1998, vol. 45, issue 3, pp. 221-229. https://doi.org/10.1016/S09396411(98)00004-6

14. Collier L.H. The development of a stable smallpox vaccine. Epidemiology and Infection. 1955, vol. 53, issue 1, pp. 76-101. htts://doi.org/10.1017/ S002217240000053X

15. Constantino H.R., Pikal M.J. Lyophilization of Biopharmaceuticals. Arlington, VA, USA: AAPS Press, 2004, $686 \mathrm{p}$.

16. Nezhuta A.A., Serbis E.S., Didenko A.A., Golovleva S.I. Certain aspects of biological material freeze-drying. Farmatsevticheskie tekhnologii $i$ upakovka. 2012, no. 4, pp. 38-40. (In Russian)

17. Nezhuta A.A., Serbis E.S. Development of scientifically-substantiated modes of freeze-drying of biological preparations. Biotekhnologiya. 2001, no. 6 , pp. 59-67. (In Russian)

18. Mogilyuk V. Aspects of lyophilized drying of aqueous solutions. Farmatsevti-cheskaya otrasl'. 2014, no. 5 (46), pp. 46-53. (In Russian)

19. Komissarov A.V., Bibikov D.N., Volokh O.A., Badarin S.A., Sinitsyna N.V., Kostyleva N.I., Germanchuk V.G., Nikiforov A.K. Lyophilization of live vaccines. Vestnik biotekhnologii $i$ fiziko-khimicheskoi biologii imeni Yu.A. Ovchinnikova. 2018, vol. 14, no. 3, pp. 56-73. (In Russian)

20. Rey L.R. Glimpses into the fundamental aspects of freeze drying. In: Development in Biological Standardization. Ed. by V.J. Cabasso, R.H. Regamey. Basel: S. Krager, 1977, vol. 16, pp. 20-27.

21. Kuzina S.M., Kulikova I.L., Khorosheva T.V., Mordvintseva E.Yu. Liofilizi-rovannaya antigerpeticheskaya vaktsina [Lyophilized antiherpetic vaccine]. Patent of RF, no. 2002115810. A61K 39/29, 2004.

22. Gavrilova M.A., Shkuratova O.V., Mal'tseva G.G., Bystritskii L.D., Ruzavina E.V. «Ospavir»novel preparation for primary vaccination against smallpox applying two-stage method. Sibirskii meditsinskii zhurnal. 2009, no. 2, issue 2, pp. 63-67. (In Russian)
23. Bystritskii L.D., Stavitskaya N.Kh., Mal'tseva G.G., Perekrest V.V., Vasil'eva T.A., Sharova O.I., Gavrilova M.A. Sposob polucheniya vaktsiny ospennoi inaktivirovannoi sukhoi "Ospavir» [Method for the production of inactivated dry smallpox vaccine «Ospavir»]. Patent of RF no. 2259214. A61K 39/285, 2005.

24. Dyatlov I.A., Somov A.N., Dunaitsev I.A., Kopylov P.Kh., Ivanov S.A., Borzilov A.l., Anisimov A.P., Khramov M.V. Rekombinantnyi vaktsinnyi preparat prolongirovannogo deistviya dlya profilaktiki chumy u mlekopitayushchikh i cheloveka i sposob ego polucheniya [Recombinant sustained-action vaccine preparation for plague prophylaxis in mammals and humans and method for its production]. Patent of RF, no. 2671525. A61K 39/02, 2018.

25. Komissarov A.V., Kochkalova N.E., Sinitsyna N.V., Badarin S.A., Kostyleva N.I., Volokh O.A., Klokova O.D., Nikiforov A.K. Studies of the freezedrying of cholera chemical vaccine immunogens. Problemy osobo opasnykh infektsii. 2016, no. 1, pp. 90-93. (In Russian). DOI: 10.21055/0370-10692016-1-90-93

26. Belyakova O.V., Nikolaeva A.M., Sosnina O.Yu., Drozhzhachikh O.S. Development and standardization of a freeze-dried form of a vaccine for the prevention of infections caused by Haemophilus influenzae type B. Permskii meditsinskii zhurnal. 2014, vol. XXXI, no. 2, pp. 102-108. (In Russian)

27. Semakova A.P., Kudryavtseva O.M., Popova P.Yu., Komissarov A.V., Mikshis N.I. Stabilization by lyophilization of immunogenic antigens of Bacillus anthracis as part of a prototype of a recombinant anthrax vaccine. Biotekhnologiya. 2017, vol. 33, no. 3, pp. 57-65. (In Russian). DOI: 10.21519/02342758-2017-33-3-57-65

28. Mikshis N.I., Semakova A.P., Popova P.Yu., Kudryavtseva O.M., Bugorkova S.A., Komissarov A.V., Germanchuk V.G., Popov Yu.A. Determination of compliance of the prototype recombinant anthrax vaccine with the requirements applicable to immunobiological preparations. Infektsiya $i$ immunitet. 2018, vol. 8, no. 3, pp. 388-392. (In Russian). https://doi.org/10.15789/2220-7619-2018-3-388-392

29. Kozhukhov V.V., Menovshchikov V.A., Pimenov E.V., Seroglazov V.V., Yudnikov V.A. Sposob polucheniya sukhoi kombinirovannoi sibireyazvennoi vaktsiny [Method for the production of dry combined anthrax vaccine]. Patent of RF, no. 2181294. A61K 39/07, 2002.

30. Kazzaz D., Kontorni M., O'Kheigan D., Singkh M., Ugozzoli M. Nabor dlya polucheniya immunogennoi kompozitsii protiv Neisseria meningitidis serologicheskoi gruppy $b$ [The panel for production of immunogenic composition against Neisseria meningitides serological group $B]$. Patent of RF, no. 2498815. A61K 39/095, 2013.

31. Amorij J-P., Saluja V., Petersen A.H., Hinrichs W.L.J., Huckriede A., Frijlink H.W. Pulmonary delivery of an inulin-stabilized influenza subunit vaccine prepared by spray-freeze drying induces sys- 
temic, mucosal humoral as well as cell-mediated immune responses in BALB/c mice. Vaccine. 2007, vol. 25 , no. 52, pp. 8707-8717. DOI: 10.1016/j.vaccine. 2007.10 .035

32. Amorij J-P., Meulenaar J., Hinrichs W.L.J., Stegmann T., Huckriede A., Coenen F., Frijlink H.W. Rational design of an influenza subunit vaccine powder with sugar-glass-technology: Preventing conformational changes of haemagglutinin during freezing and freeze-drying. Vaccine. 2007, vol. 25, no. 35, pp. 6447-6457. DOI: 10.1016/j.vaccine. 2007.06.054

33. Amorij J-P., Meulenaar J., Hinrichs W.L.J., Stegmann T., Huckriede A., Coenen F., Frijlink H.W. Inulin sugar glasses preserve the structural integrity and biological activity of influenza virosomes during freeze-drying and storage. European Journal of Pharmaceutical Sciences. 2007, vol. 32, no. 1, pp. 33-44. DOI: 10.1016/j.ejps.2007.05.112

34. Jiang G., Joshi S.B., Peek L.J., Brandau D.T., Huang J., Ferriter M.S., Woodley W.D., Ford B.M., Mar K.D., Mikszta J.A., Hwang C.R., Ulrich R., Harvey N.G., Middaugh C.R., Sullivan V.J. Anthrax vaccine powder formulations for nasal mucosal delivery. Journal of Pharmaceutical Sciences. 2006, vol. 95, no. 1, pp. 80-96. DOI: 10.1002/jps.20484

35. Czyz M., Dembczynski R., Marecik R., WojasTurek J., Milczarek M., Pajtasz-Piasecka E., Wietrzyk J., Pniewski T. Freeze-Drying of Plant Tissue Containing HBV Surface Antigen for the Oral Vaccine against Hepatitis B. BioMed Research International. 2014. Article ID 485689. DOI: $10.1155 / 2014 / 485689$

36. Ohtomo N., Mizuno K., Hamada F., Mizokami $H$. Lyophilized hepatitis $B$ vaccine. United States Patent, no. 4710378. A61K 39/00, 1987.

37. Kraan H., van Herpen P., Kersten G., Amorij J.-P. Development of Thermostable Lyophilized Inactivated Polio Vaccine. Pharmaceutical Research. 2014, vol. 31 , issue 1, pp. 2618-2629. DOI:

\subsection{7/s11095-014-1359-6}

38. Chisholm C.F., Kang T.J., Lehrer A., Donini O., Randolph T.W. Thermostable Ebola virus vaccine formulations lyophilized in the presence of aluminum hydroxide. European Journal of Pharmaceutics and Biopharmaceutics. 2019, vol. 136, pp. 213-220. DOI: 10.1016/j.ejpb.2019.01.019

39. Hassett K.J., Vance D.J., Jain N.K., Sahni N., Rabia L.A., Cousins M.C., Joshi S., Volkin D.B., Middaugh C.R., Mantis N.J., J.F. Carpenter, Randolph T.W. Glassy-State Stabilization of a Dominant Negative Inhibitor Anthrax Vaccine Containing Aluminum Hydroxide and Glycopyranoside Lipid A Adjuvants. Journal of Pharmaceutical Sciences. 2015, vol. 104, pp. 627-639. DOI: 10.1002/jps.24295

40. Hassett K.J., Meinerz N.M., Semmelmann F., Cousins M.C., Garcea R.L., Randolph T.W. Development of a highly thermostable, adjuvanted human papillomavirus vaccine. European Journal of Pharmaceutics and Biopharmaceutics. 2015, vol. 94, pp. 220-228. DOI: 10.1016/j.ejpb.2015.05.009

41. Gill D., Sharma S. Novel multivalent polysaccharide - protein conjugate vaccine composition and formulation thereof. WO/2019/003238. A61K 47/36, 2019.

42. Chintala R.V., Bhambhani $A$. HPV vaccine formulations comprising aluminum adjuvant and methods of producing same. United States Patent, no. US20170157238. A61K 39/12, 2017.

43. Huiying S., Xiubao R. Lyophilized inactivated Japanese encephalitis vaccine. Patent of China, no. CN102631672. A61K 39/12, 2014.

44. Watkinson A., Duchars M. Stable vaccine compositions and methods of use. WO/2010/084298. A61K 39/07, 2010.

45. Yoichiro K., Nobuya O. Herpes simplex virus subunit vaccine. Patent of Canada, 1244766. A61K 39/245, 1988.

\section{БИБЛИОГРАФИЧЕСКИЙ СПИСОК}

1. Plotkin S.A., Springer N.Y. History of Vaccine Development. New York: Springer, 2011. 364 p. DOI: 10.1007/978-1-4419-1339-5 6

2. Salmon D.E., Smith T. On a new method of producing immunity from contagious diseases // Proceedings of the Biological Society of Washington. 1884-1886. Vol. 3. P. 29-33.

3. Varshney D., Singh M. Lyophilized Biologics and Vaccines. Modality-Based Approaches. New York: Springer, 2015. 401 p. DOI: 10.1007/978-1-4939-2383-0

4. Pikal M.J. Freeze-drying of proteins. Part I: process design // BioPharm. 1990. Vol. 3. P. 18-28.

5. Гусаров Д.А. Лиофилизация биофармацевтических белков (миниобзор) // Биофармацевтический журнал. 2010. Т. 2. N 5. С. 3-7.

6. Wang W. Lyophilization and development of solid protein pharmaceuticals // International journal of pharmaceutics. 2000. Vol. 203. Issue 1-2. P. 1-60. https://doi.org/10.1016/S0378-5173(00)00423-3

7. Pikal M.J., Rambhatla S., Ramot R. The Impact of the Freezing Stage in Lyophilization: Effects of the Ice Nucleation Temperature on Process Design and Product Quality // Journal of the American Pharmacists Association. 2002. Vol. 5. P. 48-53.

8. Tang X., Pikal M.J. Design of Freeze-Drying Processes for Pharmaceuticals: Practical Advice // Pharmaceutical Research. 2004. Vol. 21. Issue 2. P. 191-200.

9. Franks F., Auffret T. Freeze-Drying of Pharmaceuticals and Biopharmaceuticals. Principles and Practice. Cambridge, UK: RSCPublishing, 2007. 206 p.

10. Searles J.A., Carpenter J.F., Randolph T.W. The ice nucleation temperature determines the primary drying rate of lyophilization for samples frozen on a temperature-controlled shelf // Journal of Pharmaceutical Sciences. 2001. Vol. 90. Issue 7. P. 860-871. https://doi.org/10.1002/jps.1039

11. Cochran T., Nail S.L. Ice nucleation temperature influences recovery of activity of a model protein after freeze drying // Journal of Pharmaceutical Sciences. 2009. Vol. 98. Issue 9. P. 3495-3498. DOI: 10.1002/jps.21815 
12. Heller M.C., Carpenter J.F., Randolph T.W. Protein formulation and lyophilization cycle design: prevention of damage due to freezeconcentration induced phase separation // Biotechnology and Bioengineering. 1999. Vol. 63. Issue 2. P. 166-174. DOI: $10.1002 /(\mathrm{SICl}) 1097-0290(19990420) 63: 2<166:$ : AID-BIT5>3.0.CO;2-H

13. Franks F. Freeze-drying of bioproducts: putting principles into practice // European Journal of Pharmaceutics and Biopharmaceutics. 1998. Vol. 45. Issue 3. P. 221-229. https://doi.org/10.1016/S09396411(98)00004-6

14. Collier L.H. The development of a stable smallpox vaccine // Epidemiology and Infection. 1955. Vol. 53. Issue 1. P. 76-101. htts://doi.org/10. 1017/S002217240000053X

15. Constantino H.R., Pikal M.J. Lyophilization of Biopharmaceuticals. Arlington, VA, USA: AAPS Press, 2004. 686 p.

16. Нежута А.А., Сербис Е.С., Диденко А.А., Головлева С.И. Некоторые аспекты сублимационного высушивания биоматериалов // Фармацевтические технологии и упаковка. 2012. N 4. C. $38-40$.

17. Нежута А.А., Сербис Е.С. Разработка научно обоснованных режимов сублимационной сушки биопрепаратов // Биотехнология. 2001. N 6. C. $59-67$.

18. Могилюк В. Аспекты лиофилизационной сушки водных растворов // Фармацевтическая отрасль. 2014. N 5 (46). С. 46-53.

19. Комиссаров А.В., Бибиков Д.Н., Волох О.А., Бадарин С.А., Синицына Н.В., Костылева Н.И., Германчук В.Г., Никифоров А.К. Лиофилизация живых вакцин // Вестник биотехнологии и фризикохимической биологии имени Ю.А. Овчинникова. 2018. T. 14. N 3. C. 56-73.

20. Rey L.R. Glimpses into the fundamental aspects of freeze drying. In: Development in Biological Standardization (edited by V.J. Cabasso, R.H. Regamey). Basel: S. Krager, 1977. Vol. 16. P. 20-27.

21. Пат. № 2002115810. А61K 39/29. Российская Федерация. Лиофилизированная антигерпетическая вакцина / С.М. Кузина, И.Л. Куликова,Т.В. Хорошева, Э.Ю. Мордвинцева; заявитель и патентообладатель ЗАО «Фирма "Витафарм"». Заявл. 14.06.2002; опубл. 10.02.2004.

22. Гаврилова М.А., Шкуратова О.В., Мальцева Г.Г., Быстрицкий Л.Д., Рузавина Е.В. «Оспавир» - новый препарат для первичной вакцинации против натуральной оспы двухэтапным методом // Сибирский медицинский журнал. 2009. N 2. Вып. 2. С. 63-67.

23. Пат. № 2259214. А61K 39/285. Российская Федерация. Способ получения вакцины оспенной инактивированной сухой «Оспавир» / Л.Д Быстрицкий, Н.Х. Ставицкая, Г.Г. Мальцева, В.В. Перекрест, Т.А. Васильева, О.И. Шарова, М.А. Гаврилова; заявл. 28.01.2004;опубл. 27.08.2005.

24. Пат. № 2671525. А61К 39/02. Российская Федерация. Рекомбинантный вакцинный препа- рат пролонгированного действия для профилактики чумы у млекопитающих и человека и способ его получения / И.А. Дятлов, А.Н. Сомов, И.А. Дунайцев, П.Х. Копылов, С.А. Иванов, А.И. Борзилов, А.П. Анисимов, М.В. Храмов. Заявл. 07.12.2015; опубл. 01.11.2018.

25. Комиссаров А.В., Кочкалова Н.Е., Синицына Н.В., Бадарин С.А., Костылева Н.И., Волох О.А., Клокова ОД., Никифроров А.К. Исследование процесса сублимационного высушивания иммуногенов холерной химической вакцины // Проблемы особо опасных инфекций. 2016. N 1. C. 90-93. DOI: 10.21055/0370-1069-2016-1-90-93

26. Белякова О.В., Николаева А.М., Соснина О.Ю., Дрожжачих О.С. Разработка и стандартизация лиофилизированной формы вакцины для профилактики инфекций, вызываемых Haemophilus influenzae типа $B$ // Пермский медицинский журнал. 2014. Т. XXXI. N 2. C. 102-108.

27. Семакова А.П., Кудрявцева О.М., Попова П.Ю., Комиссаров А.В., Микшис Н.И. Стабилизация путем лиофилизации иммуногенных антигенов Bacillus anthracis в составе прототипа рекомбинантной вакцины против сибирской язвы // Биотехнология. 2017. T. 33. N 3. C. 57-65. DOI: 10.21519/0234-2758-2017-33-3-57-65

28. Микшис Н.И., Семакова А.П., Попова П.Ю., Кудрявцева О.М., Бугоркова С.А. Комиссаров А.В., Германчук В.Г., Попов Ю.А. Определение соответствия прототипа рекомбинантной сибиреязвенной вакцины требованиям, предъявляемым к иммунобиологическим препаратам // Инфекция и иммунитет. 2018. Т. 8. N 3. C. 388-392. https://doi. org/10.15789/2220-7619-2018-3-388-392

29. Пат. № 2181294. А61K 39/07. Российская Федерация. Способ получения сухой комбинированной сибиреязвенной вакцины / В.В. Кожухов, В.А. Меновщиков, Е.В. Пименов, В.В. Сероглазов, В.А. Юдников. Патентообладатель НИИ Микробиологии МО РФ; заявл. 11.08.1999; опубл. 20.04.2002.

30. Пат. № 2498815. А61K 39/095. Российская Федерация. Набор для получения иммуногенной композиции против Neisseria meningitidis серологической группы В / Д. Каззаз, М. Конторни, Д. О’Хейган, М. Сингх, М. Угоззоли. Патентообладатель Novartis AG; заявл. 17.10.2008; опубл. 20.11.2013.

31. Amorij J-P., Saluja V., Petersen A.H., Hinrichs W.L.J., Huckriede A., Frijlink H.W. Pulmonary delivery of an inulin-stabilized influenza subunit vaccine prepared by spray-freeze drying induces systemic, mucosal humoral as well as cell-mediated immune responses in BALB/c mice // Vaccine. 2007. Vol. 25. No. 52. P. 8707-8717. DOI: 10.1016/j.vaccine.2007.10.035

32. Amorij J-P., Meulenaar J., Hinrichs W.L.J., Stegmann T., Huckriede A., Coenen F., Frijlink H.W. Rational design of an influenza subunit vaccine powder with sugar-glass-technology: Preventing conformational changes of haemagglutinin during 
Komissarov A.V., Bibikov D.N., Volokh O.A., et al. Lyophilisation of inactivated...

Комиссаров А.В., Бибиков Д.Н., Волох О.А. и др. Лиофилизация вакцин, не содержащих...

freezing and freeze-drying // Vaccine. 2007. Vol. 25. No. 35. P. 6447-6457. DOI: 10.1016/j.vaccine.2007. 06.054

33. Amorij J-P., Meulenaar J., Hinrichs W.L.J., Stegmann T., Huckriede A., Coenen F., Frijlink H.W. Inulin sugar glasses preserve the structural integrity and biological activity of influenza virosomes during freeze-drying and storage // European Journal of Pharmaceutical Sciences. 2007. Vol. 32. No. 1. P. 33-44. DOI: 10.1016/j.ejps.2007.05.112

34. Jiang G., Joshi S.B., Peek L.J., Brandau D.T., Huang J., Ferriter M.S., Woodley W.D., Ford B.M., Mar K.D., Mikszta J.A., Hwang C.R., Ulrich R., Harvey N.G., Middaugh C.R., Sullivan V.J. Anthrax vaccine powder formulations for nasal mucosal delivery // Journal of Pharmaceutical Sciences. 2006. Vol. 95. No. 1. P. 80-96. DOI: 10.1002/jps.20484

35. Czyz M., Dembczynski R., Marecik R., Wojas-Turek J., Milczarek M., Pajtasz-Piasecka E., Wietrzyk J., Pniewski T. Freeze-Drying of Plant Tissue Containing HBV Surface Antigen for the Oral Vaccine against Hepatitis B // BioMed Research International. 2014. Article ID 485689. DOI: 10.1155/2014/485689

36. Ohtomo N., Mizuno K., Hamada F., Mizokami H. Lyophilized hepatitis $B$ vaccine. United States Patent no. 4710378. A61K 39/00. 1987.

37. Kraan H., van Herpen P., Kersten G., Amorij J.-P. Development of Thermostable Lyophilized Inactivated Polio Vaccine // Pharmaceutical Research. 2014. Vol. 31. Issue 1. P. 2618-2629. DOI: 10.1007/s11095-014-1359-6

38. Chisholm C.F., Kang T.J., Lehrer A., Donini O., Randolph T.W. Thermostable Ebola virus vaccine formulations lyophilized in the presence of aluminum

\section{Contribution}

Alexander V. Komissarov, Dmitry N. Bibikov, Oksana A. Volokh, Sergey A. Badarin, Nataliya V. Sinitsyna, Nataliya I. Kostyleva, Aleksey K. Nikiforov carried out the experimental work, on the basis of the results summarized the material and wrote the manuscript. Alexander V. Komissarov, Dmitry N. Bibikov, Oksana A. Volokh, Sergey A. Badarin, Nataliya V. Sinitsyna, Nataliya I. Kostyleva, Aleksey K. Nikiforov have equal author's rights and bear equal responsibility for plagiarism.

\section{Conflict of interests}

The authors declare no conflict of interests regarding the publication of this article.

\section{AUTHORS' INDEX}

Alexander V. Komissarov,

Dr.Sci. (Biology), Associate Professor,

Chief Researcher,

Russian Research Anti-Plague Institute «Microbe»;

Professor,

N.I. Vavilov Saratov State Agrarian University,

Microbiology, Biotechnology, and

Chemistry Department,

$\bowtie$ e-mail: Komissarov-9@yandex.ru hydroxide // European Journal of Pharmaceutics and Biopharmaceutics. 2019. Vol. 136. P. 213-220. DOI: 10.1016/j.ejpb.2019.01.019

39. Hassett K.J., Vance D.J., Jain N.K., Sahni N., Rabia L.A., Cousins M.C., Joshi S., Volkin D.B., Middaugh C.R., Mantis N.J., J.F. Carpenter, Randolph T.W. Glassy-State Stabilization of a Dominant Negative Inhibitor Anthrax Vaccine Containing Aluminum Hydroxide and Glycopyranoside Lipid A Adjuvants // Journal of Pharmaceutical Sciences. 2015. Vol. 104. P. 627-639. DOI: 10.1002/jps.24295

40. Hassett K.J., Meinerz N.M., Semmelmann F., Cousins M.C., Garcea R.L., Randolph T.W. Development of a highly thermostable, adjuvanted human papillomavirus vaccine // European Journal of Pharmaceutics and Biopharmaceutics. 2015. Vol. 94. P. 220-228. DOI: 10.1016/j.ejpb.2015.05.009

41. Gill D., Sharma S. Novel multivalent polysaccharide - protein conjugate vaccine composition and formulation thereof. WO/2019/003238. A61K 47/36. 2019.

42. Chintala R.V., Bhambhani A. HPV vaccine formulations comprising aluminum adjuvant and methods of producing same. United States Patent no. US20170157238. A61K 39/12. 2017.

43. Huiying S., Xiubao R. Lyophilized inactivated Japanese encephalitis vaccine. China Patent no. CN102631672. A61K 39/12. 2014.

44. Watkinson A., Duchars $M$. Stable vaccine compositions and methods of use. WO/2010/084298. A61K 39/07. 2010.

45. Yoichiro K., Nobuya O. Herpes simplex virus subunit vaccine. Canadian Patent 1244766. A61K 39/245. 1988.

\section{Критерии авторства}

Комиссаров А.В., Бибиков Д.Н., Волох О.А., Бадарин С.А., Синицына Н.В., Костылева Н.И., Никифоров А.К. выполнили экспериментальную работу, на основании полученных результатов провели обобщение и написали рукопись. Комиссаров А.В., Бибиков Д.Н., Волох О.А., Бадарин С.А., Синицына Н.В., Костылева Н.И., Никифоров А.К. имеют на статью равные авторские права и несут равную ответственность за плагиат.

\section{Конфликт интересов}

Авторы заявляют об отсутствии конфрликта интересов.

\section{СВЕДЕНИЯ ОБ АВТОРАХ}

Комиссаров Александр Владимирович, д.б.н., доцент, главный научный сотрудник, Российский научно-исследовательский противочумный институт «Микроб»; профрессор кафедры микробиологии, биотехнологии и химии, Саратовский государственный аграрный университет им. Н.И. Вавилова, $\bowtie$ e-mail: Komissarov-9@yandex.ru 
Komissarov A.V., Bibikov D.N., Volokh O.A., et al. Lyophilisation of inactivated...

Комиссаров А.В., Бибиков Д.Н., Волох О.А. и др. Лиофилизация вакцин, не содержащих...

Dmitry N. Bibikov,

Research Assistant,

Russian Research Anti-Plague Institute «Microbe», e-mail: rusrapi@microbe.ru

\section{Oksana A. Volokh,}

Ph.D. (Biology), Head of the Department,

Russian Research Anti-Plague Institute «Microbe», e-mail: rusrapi@microbe.ru

\section{Sergey A. Badarin,}

Researcher,

Russian Research Anti-Plague Institute «Microbe», e-mail: rusrapi@microbe.ru

\section{Nataliya V. Sinitsyna,}

Researcher,

Russian Research Anti-Plague Institute «Microbe», e-mail: rusrapi@microbe.ru

\section{Nataliya I. Kostyleva,}

Researcher,

Russian Research Anti-Plague Institute «Microbe», e-mail: rusrapi@microbe.ru

\author{
Aleksey K. Nikiforov, \\ Dr. Sci. (Biology), Associate Professor, \\ Deputy Director, \\ Russian Research Anti-Plague Institute «Microbe»; \\ Professor, \\ Microbiology, Biotechnology, and \\ Chemistry Department, \\ N.I. Vavilov Saratov State Agrarian University, \\ e-mail: rusrapi@microbe.ru
}

Бибиков Дмитрий Николаевич, младший научный сотрудник, Российский научно-исследовательский противочумный институт «Микроб», e-mail: rusrapi@microbe.ru

\section{Волох Оксана Александровна,} к.б.н., заведующая отделом, Российский научно-исследовательский противочумный институт «Микроб», e-mail: rusrapi@microbe.ru

\section{Бадарин Сергей Анатольевич,} научный сотрудник, Российский научно-исследовательский противочумный институт «Микроб», e-mail: rusrapi@microbe.ru

\section{Синицына Наталья Викторовна,} научный сотрудник, Российский научно-исследовательский противочумный институт «Микроб», e-mail: rusrapi@microbe.ru

\section{Костылева Наталья Ивановна,} научный сотрудник, Российский научно-исследовательский противочумный институт «Микроб», e-mail: rusrapi@microbe.ru

\section{Никифроров Алексей Константинович,} д.б.н., доцент, заместитель директора, Российский научно-исследовательский противочумный институт «Микроб»; профессор кафедры микробиологии, биотехнологии и химии, Саратовский государственный аграрный университет им. Н.И. Вавилова e-mail: rusrapi@microbe.ru 